22 Duke Envtl. L. \& Pol'y F. 1

Duke Environmental Law and Policy Forum

Fall 2011

Article

\title{
THE LIMITS OF LIABILITY IN PROMOTING SAFE GEOLOGIC SEQUESTRATION OF CO2
}

\author{
David E. Adelman, Ian J. Duncan ${ }^{\mathrm{d} 1}$
}

Copyright (c) 2011 Duke Environmental Law \& Policy Forum; David E. Adelman; Ian J. Duncan

\begin{abstract}
Introduction
Deployment of new technologies is vital to climate change policy, but it invariably poses difficult tradeoffs. Carbon capture and storage (CCS), which involves the capture and permanent burial of $\mathrm{CO}_{2}$ emissions, exemplifies this problem. Public acceptance of CCS faces an uphill battle. CCS lacks the green appeal of renewable sources of power, and disbelief is an all too common response of laypeople when they are told that billions of tons of $\mathrm{CO}_{2}$ can be stored underground for centuries. Further, despite its twin virtues of (relatively) low projected costs and enormous capacity to mitigate $\mathrm{CO}_{2}$ emissions, knowledgeable stakeholders often dismiss CCS as either unworkable or as an enabling technology for energy sources and industries that should be abandoned or retooled. 1
\end{abstract}

CCS is nevertheless promoted by a broad range of prominent stakeholders who assert that avoiding climate change will be impossible without it.? Steven Chu, the U.S. Secretary of Energy, has argued that public support of CCS is critical and that the United States should "act with fierce urgency" to develop and deploy it. - Several prominent environmental organizations, including the *2 Natural Resources Defense Council, the Environmental Defense Fund, and the Pew Center on Global Climate Change, have each endorsed CCS notwithstanding their aversion to coal-based power, which would be a primary beneficiary of this technology.. Similarly, the European Commission, which has been a leader in global efforts to combat climate change, maintains that "we cannot reduce EU or world $\mathrm{CO}_{2}$ emissions by $50 \%$ in 2050 if we do not also use [CCS]" and has enacted a detailed directive to promote it..

The importance that stakeholders and governments attach to CCS is strongly associated with its scale, which could rival that of the largest industries on the planet. A single, mid-size coal-fired power plant emits about 3 million metric tons of $\mathrm{CO}_{2}$ per year.- The corresponding daily volume of compressed $\mathrm{CO}_{2}$ would fill a supertanker every 15 days, ${ }^{\underline{T}}$ and scientists estimate that the subsurface $\mathrm{CO}_{2}$ plume would encompass an area of 240 square kilometers after 40 years of operation..$-\frac{8}{\text { These }}$ numbers illustrate the acute need for large-scale technologies to mitigate $\mathrm{CO}_{2}$ emissions. However, the advantage of the enormous scale of CCS is also a source of stakeholder concern because it suggests that the risks are large as well. ${ }^{2}$ Thus, the large scale of CCS is simultaneously a necessity and an obstacle to its deployment.

*3 A combination of factors--including uncertainties about the cost of CCS, low public awareness and understanding of the technology and risks, and the many years it will take to commercialize--have contributed to the relative obscurity of CCS. ${ }^{10}$ In contrast to this lack of public engagement, an intense battle over CCS has erupted among policy analysts, technical experts, and lawyers. ${ }^{11}$ Beyond concerns about the high costs of capturing $\mathrm{CO}_{2}$, two issues have dominated the debate: (1) the risks posed by leakage of $\mathrm{CO}_{2}$ from sequestration sites, and (2) management of the long-term liabilities (possibly extending hundreds of years) associated with the sites. $\frac{12}{}$

Skeptical academics have also complained that no risk management framework has been devised that ensures funding will be available to take remedial action or to compensate victims for the effects of harmful releases from sequestration sites while 
also avoiding the problem of moral hazard. $\frac{13}{}$ This conflict is alleged to arise because responsibility for sequestration sites will likely be ultimately transferred to a government entity for long-term stewardship..$^{14}$ The incipient CCS industry has reinforced these fears by decrying the crippling effect that open-ended liability would have on CCS deployment, $\frac{15}{2}$ a position some prominent academics and advocates have accepted and often amplified..$\underline{16}$

*4 We argue that these fears are being fueled by misapprehensions about the risks posed by sequestration sites. A central challenge for CCS policy development is the potential for decision-makers to draw false analogies from prior experience. Controversial federal legislation, notably remediation of contaminated properties under Superfund and regulation of nuclear power under the Atomic Energy Act, have often framed the debate. ${ }^{17}$ However, while similarities exist, sequestration of $\mathrm{CO}_{2}$ does not present either the causal intricacies or the severity of harms that have defined these programs. $\frac{18}{-}$

The primary risks from sequestration sites are negative impacts on drinking-water aquifers from either leakage of $\mathrm{CO}_{2}$ or intrusion of native salt-laden waters (brines), which could be driven upward from sequestration reservoirs by the elevated pressures that result from $\mathrm{CO}_{2}$ injection. $\frac{19}{}$ While contamination of drinking-water aquifers could trigger significant remediation costs, it is highly unlikely that these costs would be crippling, ${ }^{20}$ and the threats bear little resemblance to the large, chemically complex releases that made Superfund infamous. .11

These misunderstandings have been exacerbated by the focus of stakeholders--and until recently also of scientists--on $\mathrm{CO}_{2}$ leakage *5 alone. ${ }^{22}$ This oversight is in large part a product of evolving scientific understanding; only recently have new studies revealed that the most significant risks are likely to derive from releases of reservoir brines. $\frac{23}{}$ The most significant difference between releases of $\mathrm{CO}_{2}$ and brine is the geographic scope. While scientists estimate that $\mathrm{CO}_{2}$ plumes in sequestration reservoirs will extend several kilometers from a $\mathrm{CO}_{2}$ injection well, they estimate that the area of elevated pressure in which brines could be forced into overlying aquifers will extend across tens of kilometers. $\frac{24}{4}$

The larger areas involved and the indirect nature of the impacts will create unique challenges for effective regulation and novel factual settings for liability. However, the large scale of $\mathrm{CO}_{2}$ sequestration is not entirely a negative, as large operations also offer economies of scale for regulation. And while impacts from releases could occur over vast areas, these impacts are well understood and relatively straightforward to mitigate, if not to prevent. ${ }^{25}$ Put differently, the risks are remarkably small relative to the volume of $\mathrm{CO}_{2}$ involved and the subsurface area covered by a typical sequestration site.

Arguably, our most surprising conclusion is the modest role that common law liability is likely to play in promoting safe sequestration of $\mathrm{CO}_{2}$. The limiting factors are the types of harms, outlined above, and their timing. While the conventional belief among CCS advocates is that risks will decline rapidly in the decades after $\mathrm{CO}_{2}$ injection ends, ${ }^{26}$ new scientific studies are challenging this simple picture. These *6 studies have demonstrated that geologic features such as faults and reservoir permeability, and human infrastructure such as abandoned wells, will create a mix of near-and long-term risks, some of which could persist for many decades. ${ }^{27}$

The combination of risks with different temporal profiles will limit the role that liability can play. Economists have long

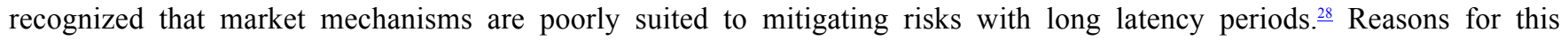
shortcoming include economic discounting, the short-term focus of business planning, and the limited tenure of business executives..$^{29}$ The timing of risks is therefore an important constraint, as liability regimes are better at managing near-term risks. More to the point, if long-term liability offers only nominal deterrence, then the specter of moral hazard and CCS industry fears about open-ended liability that have received so much attention are groundless.

This article proceeds in four parts. Part I provides an overview of CCS, focusing on geologic sequestration, and analyzes the scientific work on the potential for releases of $\mathrm{CO}_{2}$ and brine from sequestration reservoirs. Part II evaluates the comparative advantages of government regulation and common law liability; this background leads into a critical analysis of current concerns about long-term liability and moral hazard. Part III examines the relative efficiencies of different doctrines of common law liability when applied to likely releases from sequestration sites. We find support for negligence and strict liability, but the deterrence value of both doctrines will be limited to a subset of important near-term risks. Collectively these sections demonstrate that the current debate misdiagnoses the primary risks and overlooks operational factors that simplify application of common law liability. In part IV we propose a hybrid legal framework that combines a traditional regulatory 
regime *7 with a novel two-tiered system of liability that is calibrated to objective site characteristics. This framework balances principles of economic efficiency and the realities of political viability.

\section{Timing and Magnitude of the Risks Posed by Carbon Sequestration}

The basic elements of CCS are straightforward enough to describe at a general level. $\mathrm{CO}_{2}$ is captured from the flue gas of an industrial source (such as a power plant, oil refinery, or cement kiln), compressed into a supercritical fluid ${ }^{30}$ for transportation to a sequestration site, and then injected into a deep brine reservoir, typically 3,000 to 10,000 feet underground, for permanent disposal. $\frac{31}{-}$ Although the capture and compression of $\mathrm{CO}_{2}$ are responsible for the bulk of the costs and many of the most challenging technological hurdles for $\mathrm{CCS}, \frac{32}{-}$ geologic sequestration of $\mathrm{CO}_{2}$ has raised the most contentious legal and policy issues.

This one-sided focus on geologic sequestration likely stems from the similarities of $\mathrm{CO}_{2}$ capture systems to other large-scale chemical processing facilities, with which people are familiar, whereas few people have experience with underground disposal of chemicals. The public's unfamiliarity owes much to the inherent obscurity of subsurface waste disposal, which is carried out in some industries (mostly by the oil and chemical sectors) at levels that are comparable to or exceed those anticipated for CCS..$\frac{33}{-}$ This focus has also been $* \mathbf{8}$ inflamed by dramatic, though not representative, incidents involving rapid releases of $\mathrm{CO}_{2}$, most notably the death of more than 1700 people when a huge bubble of $\mathrm{CO}_{2}$ from an underlying volcanic source was released from Lake Nyos in Cameroon. $\frac{34}{}$

The massive volumes of $\mathrm{CO}_{2}$ produced globally are, by most accounts, more than matched by the available subsurface storage space in geologic reservoirs. $\frac{35}{}$ Various benchmarks are used to illustrate the magnitude of national and global carbon emissions. In the United States, for example, using CCS to eliminate $50 \%$ of $\mathrm{CO}_{2}$ emissions from the current fleet of coalfired power plants would involve transporting and sequestering a volume of $\mathrm{CO}_{2}$ roughly equal to the volume of oil consumed annually. $\frac{36}{-}$ Similarly, at the global level, sequestering just $15 \%$ of aggregate $\mathrm{CO}_{2}$ emissions would require infrastructure that could handle volumes of $\mathrm{CO}_{2}$ that exceed those of world oil production. $\frac{37}{-}$

Recent estimates indicate that depleted oil and gas reservoirs could store 900 to 1200 gigatons of $\mathrm{CO}_{2}(\mathrm{one}$ gigaton $(\mathrm{Gt})$ is one billion metric tons), while the capacity of deep saline reservoirs is conservatively projected to exceed $1000 \mathrm{Gt}$ of $\mathrm{CO}_{2}$ and

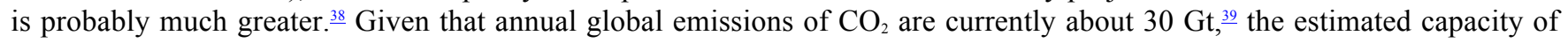
deep brine reservoirs is sufficient to sequester the equivalent of 30 to 40 years of total global $\mathrm{CO}_{2}$ emissions or approximately 75 to 125 years of the $* 9$ emissions from the power sector..$^{40}$ Despite the large reservoir capacities available, constraints on carbon-capture technologies, limited funding, and high construction costs will limit the use of CCS to a fraction of its storage potential, making it viable as a bridge technology for substantially longer than these estimates suggest. ${ }^{-1}$

Geologic sequestration occurs in tiny cavities, or "pore spaces," that are intrinsic to most sedimentary rocks. $\stackrel{42}{ }$ At a crude level of description, the Earth's crust consists of two basic types of rock--igneous and sedimentary. As the latter name suggests, sedimentary rocks are formed from thick accumulations of sand, clay, salts, and silt over millions of years. The resulting rock is interspersed with porous and permeable layers (sand) as well as impermeable layers (clay, silt, salt). $\frac{43}{-}$ Basins of sedimentary rock typically contain thousands of cubic meters of porous sediments that are filled with water that is saltier than seawater (hence these basins are called "brine reservoirs")..$^{44}$ The layers of clay, silt, and salt provide impermeable "cap rock" that is a natural barrier to movement of $\mathrm{CO}_{2}$, which would otherwise be carried upward as it is more buoyant than water. ${ }^{45}$ Injected $\mathrm{CO}_{2}$, which displaces the brine in a sedimentary formation, ${ }^{46}$ will be permanently immobilized by chemical processes (for example, by dissolution into the brine) that operate on timescales ranging from tens to hundreds of years. ${ }^{47}$

Despite encouraging statistics and science, the proposal to bury billion of tons of $\mathrm{CO}_{2}$ underground for centuries is understandably viewed as a dubious form of geoengineering by some. In fact, this kind of response ought to be expected because few people have experience with large-scale industries, and fewer still are comfortable with the geological scales of carbon sequestration. And yet substantial *10 precedent exists for carbon sequestration in natural and industrial settings.

The trapping capacity of sedimentary basins has been exhaustively studied, in part because oil, gas, and $\mathrm{CO}_{2}$ have been 
naturally trapped in sedimentary formations for millions of years. $\frac{48}{}$ As alluded to above, industries have been storing and

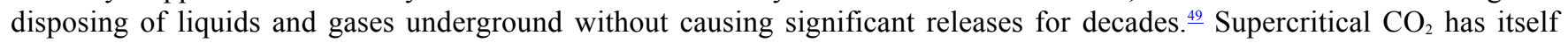
been used for nearly four decades to facilitate oil production. This process also involves pumping large volumes of $\mathrm{CO}_{2}$ underground, and its safety record is excellent. $\underline{50}$ Moreover, the technologies needed for drilling into deep brine reservoirs, injecting $\mathrm{CO}_{2}, \frac{51}{1}$ and monitoring sequestration sites are well developed, although more elaborate site characterization and monitoring will be required to deploy CCS at full scale. .5 Thus, despite its apparent novelty, sequestration of $\mathrm{CO}_{2}$ in geologic formations is not a wildly speculative gambit, but is instead based on extensive (though clearly still evolving) scientific work and years of engineering experience with technically similar projects.

\section{A. Types of Risks}

Like any complex engineering problem, especially one reliant on the difficult-to-access details of subsurface geology, $\mathrm{CO}_{2}$ sequestration projects will not be risk-free. The potential risks are, however, relatively well understood and expected to be manageable, particularly in comparison to the technical uncertainties typical of terrestrial sequestration of $\mathrm{CO}_{2} \cdot \frac{53}{5} \mathrm{Most}^{-}$ scientists believe that releases of $\mathrm{CO}_{2}$ or brines into groundwater will be the two major sources of environmental risk,,$\frac{54}{4}$ although some scientists have also suggested *11 that seismic activity could be induced by $\mathrm{CO}_{2}$ injection. $\frac{55}{}$ Even they acknowledge, though, that seismicity is unlikely and is preventable with proper siting, installation, and monitoring. $\frac{56}{6}$

We will focus on the risks posed by releases of $\mathrm{CO}_{2}$ and brine. The most significant form of environmental harm from such releases is predicted to be contamination of drinking water by, for example, mobilization of toxic metals or increased salinity. .5 While other harms are possible, such as asphyxiation from $\mathrm{CO}_{2}$ accumulating in the basements of buildings or $\mathrm{CO}_{2}$ in soils killing plants, $\frac{58}{t}$ they are believed to be of secondary importance due to their very remote likelihood. $\frac{59}{}$ Taking into account singular events like the release of $\mathrm{CO}_{2}$ from Lake Nyos, little or no evidence exists that direct atmospheric releases of $\mathrm{CO}_{2}$ could be a significant threat to humans. .0

*12 Abandoned wells and faults in cap rock are believed to be the primary pathways for releases of $\mathrm{CO}_{2}$ or brine. ${ }^{61}$ The risk of leakage through abandoned wells arises because wellbores can corrode and cements can chemically degrade over time..$\underline{62}$ At the extremes, releases could be near term and involve large volumes of $\mathrm{CO}_{2}$, such as a release from a poorly capped well in the immediate vicinity of a $\mathrm{CO}_{2}$ injection well, or they could involve very slow leaks, for example, through small, undetected subsurface faults in sedimentary cap rock. $\cdot \frac{63}{}$ Experts believe that careful site selection and characterization, along with early-detection systems for leakage, can reduce the impacts of such releases..$^{64}$

\section{*13 B. $\mathrm{CO}_{2}$ Plumes and Brine Displacement in Sequestration Reservoirs}

The two primary sources of risk to groundwater--direct release of $\mathrm{CO}_{2}$ and pressure-driven intrusion of brines--have significantly different risk profiles. $\frac{65}{}$ While the elevated pressures associated with injection of $\mathrm{CO}_{2}$ cause movement of both $\mathrm{CO}_{2}$ and brine, the pressure field will have effects far beyond the maximum extent of the $\mathrm{CO}_{2}$ plume. $\frac{66}{}$ These pressure effects will cause subsurface fluid flow, which, depending on the permeability and morphology of the sedimentary basin, could cause reservoir brines to be forced through an upward sloping sedimentary rock layer that leads to nearby or (more likely) distant wells used for drinking water. ${ }^{67}$ Releases could also occur when either a $\mathrm{CO}_{2}$ plume or brine within a zone of elevated pressure encounters a fault in the cap rock or an abandoned well that is incompletely capped..$\underline{68}$

The risks associated with leakage of $\mathrm{CO}_{2}$ and movement of brine into aquifers will not be identical in magnitude or timing. Leakage of $\mathrm{CO}_{2}$ will not be dependent on the elevated pressures around an injection well, as the buoyancy of $\mathrm{CO}_{2}$ is sufficiently high to drive it to *14 the surface and to propel it laterally. ${ }^{-69} \mathrm{By}$ contrast, because brine intrusion is driven by elevated pressure, the potential area of risk in the reservoir will continue to expand for many decades after $\mathrm{CO}_{2}$ injection

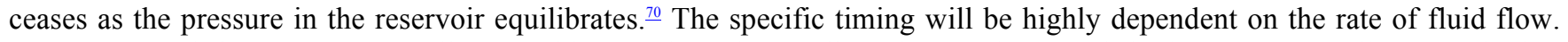
Reservoirs with low resistance will re-equilibrate relatively rapidly, whereas those with high resistance will sustain higher pressures around injection wells, and it will take much longer for the pressure fields to expand and dissipate. ${ }^{11}$ 
The potential for $\mathrm{CO}_{2}$ or pressurized brine to encounter a transmissive fault or wellbore increases with subsurface area; as a consequence, the aggregate risk of releases will rise with the areal extent of both the $\mathrm{CO}_{2}$ plume and the zone of elevated pressure. ${ }^{72}$ The risk of $\mathrm{CO}_{2}$ leakage will decline as chemical processes immobilize it, whereas the likelihood of brine intrusion will be solely a function of the pressure in the reservoir. Understanding the dynamics of $\mathrm{CO}_{2}$ plumes and the spread of pressure from an injection well is therefore essential to understanding the primary risks associated with sequestration sites.

The recognition that the pressure effects of $\mathrm{CO}_{2}$ injection will travel much more rapidly and for far greater distances than the $\mathrm{CO}_{2}$ plume itself is arguably the single most important result of recent scientific work on geologic sequestration. ${ }^{73}$ In a 2008 simulation study $* \mathbf{1 5}$ that incorporated detailed empirical data on subsurface conditions in Texas, the researchers found that 50 years after the end of active $\mathrm{CO}_{2}$ injection, the $\mathrm{CO}_{2}$ plume would extend just 3 to 5 kilometers from the injection well, whereas the field of elevated pressure was projected to extend many tens of kilometers from the well. . $^{74}$ Several other independent models have generated similar results, with the $\mathrm{CO}_{2}$ plumes spanning several kilometers and the much larger pressure fields extending tens of kilometers from injection wells. $\stackrel{75}{ }$

A recent modeling study of particular note ran a series of simulations involving multiple injection wells in a reservoir located in Illinois. ${ }^{76}$ The simulations predicted that $\mathrm{CO}_{2}$ migration would be slow, on average 3.3 meters per year post-injection, such that in one representative simulation, the plume did not reach the cap rock after 200 years..$^{77}$ In the same study, the maximum lateral length of the $\mathrm{CO}_{2}$ plumes was estimated to be $5.5 \mathrm{~km}$ (about 3 miles) after 50 years and just $13.5 \mathrm{~km}(8$ miles) after 200 years, with no direct plume interference between storage sites during this period. $\frac{78}{}$ The simulations also found that after 200 years "the vast majority of the injected $\mathrm{CO}_{2}$ [was] contained via residual and solubility trapping, leaving only $13 \%$ as mobile phase." ${ }^{\prime \prime 9}$ This result suggests that the risk of $\mathrm{CO}_{2}$ leakage can drop dramatically within the first hundred or so years after a site transitions to permanent closure and long-term management (often referred to as "long-term stewardship").

The Illinois basin study adds further support for the importance of brine intrusion, despite predicting that reservoir pressure would drop rapidly and then plateau at about 100 years after the end of $\mathrm{CO}_{2} * 16$ injection... The model simulations projected that the areas of elevated pressure sufficient to cause brine intrusion would extend $150 \mathrm{~km}$ from the injection wells. $\frac{81}{}$ The areas of elevated pressure also spread quickly; interactions between wells were found within half a year, and reservoir pressure effects (which extended beyond the $275 \mathrm{~km}$ radius) were indivisible between the twenty wells by the end of 50 years of active $\mathrm{CO}_{2}$ injection..$\underline{82}$

This study also simulated the effects of faults in cap rock, of leaky abandoned wells, and of flow outside of the model boundary. The model predicted very little brine movement of any kind (that is, flow through cap rock breaches or the lateral

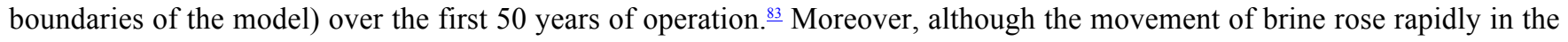
simulations over the 50 year injection period (reaching a maximum rate after 63 years), movement of brine was not the primary mechanism for accommodating the injected $\mathrm{CO}_{2}$ until more than 150 years after injection was initiated..$^{84}$ It was not until 200 years had passed that leakage through faults and abandoned wells in the core injection area accounted for approximately one-third of the brine displaced by the injected $\mathrm{CO}_{2}$, but even with the substantial volumes of brine mobilized,

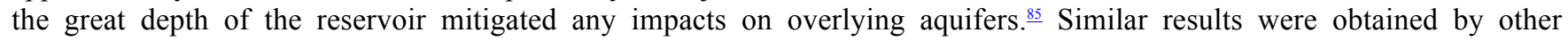
researchers using a different model and alternative assumptions; they estimated delays for detectable impacts on overlying aquifers of 50 to 150 years after $\mathrm{CO}_{2}$ injection had ceased. $\frac{86}{6}$

The results of these recent studies have important implications for regulatory policies and potential liabilities associated with sequestration sites. At the broadest level, the potential for brine intrusion into valuable sources of drinking water may be the factor that determines the capacity and hence the viability of sequestration sites. $\stackrel{87}{ }$ The enormous subsurface areas of elevated pressure around *17 sequestration sites will exacerbate the regulatory burdens and the technical challenges of site characterization because areas of regulatory significance could exceed 100,000 square $\mathrm{km}$ for a single site. $\stackrel{88}{=}$ Similarly, because zones of elevated pressure will extend far beyond a given injection well, and interactions between them will arise rapidly, permitting of sequestration sites should be coordinated across different wells..$\underline{9}$

If the recent scientific work is borne out, liability for releases of brine from a sequestration reservoir with multiple injection sites will be indivisible within a few years after the start of $\mathrm{CO}_{2}$ injection. .0 Further, because brine intrusion is driven by elevated pressures, which spread rapidly and can persist for many decades, no ascertainable transport of a substance (water 
and salt molecules are perfectly fungible) will occur across the reservoir. This is as pure an example of indivisible causation for a tort as one could expect to find.1 $\mathrm{By}$ contrast, the $\mathrm{CO}_{2}$ plumes are projected to remain localized for many decades, thereby minimizing the potential for physical overlap and avoiding divisibility problems with assigning liability. These results expose the heightened risks presented by releases of brine from sequestration reservoirs. They are both more probable and likely to be of longer duration than releases of $\mathrm{CO}_{2}$, and the degree to which concerns about direct leakage of $\mathrm{CO}_{2}$ have been overemphasized and ought to be reassessed.

The emerging scientific work on sequestration of $\mathrm{CO}_{2}$ and decades of experience in the oil and gas industries demonstrate that uncertainties about risks will remain even under the best circumstances. $\frac{92}{\text { Th }}$ This should not be read to preclude bounded estimates of risks, as several recent efforts to formulate risk assessment frameworks indicate that such estimates are feasible..$^{\underline{93}}$ *18 These works suggest that established methods of subsurface characterization and modeling should be able to provide reasonable estimates of potential risks. Relatively simple metrics, such as the number of wells in the area, the density of faults, and the permeability of a reservoir, can be used in intuitively tractable and transparent models to establish conservative upper bounds for the most important sources of risk from sequestration sites. ${ }^{94}$

\section{Sequestration of $\mathrm{CO}_{2}$ and Carbon Accounting}

The monitoring, reporting, and verification (MRV) of $\mathrm{CO}_{2}$ emissions offsets is among the most politically contentious and technically challenging issues impeding global efforts to address climate change. $\frac{95}{\text { Th }}$ The limited experience that exists for offsetting $\mathrm{CO}_{2}$ emissions suggests that MRV for other forms of climate change mitigation (such as reforestation projects) is likely to be even more technically complex and politically divisive than for CCS.

Against this backdrop, CCS has a number of relative virtues, even if the potential challenges of accurately determining leakage rates from sequestration reservoirs are taken into account. At the outset, the large scale of CCS systems makes them a relatively easy target for regulation, and unlike many forms of terrestrial sequestration, ${ }^{96}$ the amount of $\mathrm{CO}_{2}$ that is captured and sequestered underground is susceptible to direct measurement that is both precise and accurate. ${ }^{97}$ Scientists are also confident that leakage of $\mathrm{CO}_{2}$ from *19 well-managed sequestration sites is "likely to be small in magnitude and distant in time. $\underline{.98}$

Significant technical challenges and uncertainties nevertheless remain regarding capacities to monitor fugitive emissions and reservoir leakage. Technical experts believe that fugitive emissions from large-scale industrial systems used to capture, transport, and inject $\mathrm{CO}_{2}$ can be estimated with a reasonable degree of accuracy and consistent with existing reporting methods..9 Qualitative methods exist for estimating leakage rates from reservoirs, and some commentators have suggested that they could be supplemented by measuring surface fluxes of $\mathrm{CO}_{2} \cdot{ }^{100}$ (We are skeptical, given the natural variability in background levels of $\mathrm{CO}_{2}$.) Large leaks will be readily detectible, and in most cases (such as leakage through abandoned wells), they will be rapidly closed. $\stackrel{101}{ }$ A major impediment is simply that data on reservoir leakage are extremely limited, as it has only just recently become the subject of intensive scientific study. $\frac{102}{}$

In sum, CCS appears to have several advantages over other methods of offsetting $\mathrm{CO}_{2}$ emissions, and although it has significant technical limitations, the limitations of the potential alternatives are likely to be much more severe. ${ }^{103}$ Moreover, while it is possible that the large scale of CCS could backfire, for example, if a large leak in a reservoir were to arise and could not be plugged, the probability of such an occurrence is believed to be exceedingly slight. ${ }^{104}$ The relative ease of $\mathrm{CO}_{2}$ accounting provides an independent motivation for deploying CCS and has important implications for the efficient operation of common law liability.

\section{*20 II. The Importance of Ex Ante Regulation and the Absence of Moral Hazard}

Sequestering $\mathrm{CO}_{2}$ underground for approximately 1,000 years will push the bounds of governments' institutional capacities and legal frameworks. ${ }^{105}$ Environmental risks that span long timeframes pose particularly challenging problems for both ex ante regulations and ex post liability regimes. $\stackrel{106}{\text { At }}$ the most basic level, very few human institutions have lifespans in the 
hundreds of years. Leaders of public and private institutions themselves have short time horizons, often estimated to be on the order of 10 to 15 years,, 07 and this bias is reinforced by the difficulties of holding decision-makers accountable for impacts of decisions that arise decades into the future. .08

The debate over regulation of carbon sequestration recognized these temporal challenges early on. As a consequence, proposed policies have included complete transfer of liability to the government after an active post-closure period for a site, partial transfer of long-term liability to the government with companies retaining liability up to a legally prescribed limit, as well as conventional open-ended corporate liability. .09 Yet, while there is broad consensus that responsibility for carbon sequestration sites should ultimately be transferred to the federal government, many questions have been raised about how and when this should occur. 110

There appears to be general agreement that traditional state common law doctrines alone cannot effectively address the risks

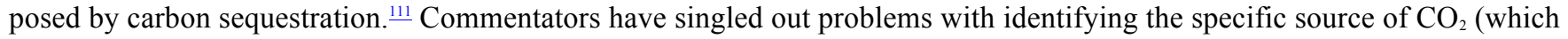
may occur if multiple companies sequester $\mathrm{CO}_{2}$ in the same or spatially $* 21$ overlapping deep brine reservoirs) and the extremely long timescale over which leakage of $\mathrm{CO}_{2}$ can occur. $\stackrel{112}{ }$ Proposed legal responses have included enhanced forms of tort liability (such as strict liability or joint and several liability), insurance requirements, establishment of a federal funding pool, and bonding requirements. $\underline{\underline{113}}$

Virtually all of the proposed policies are multilayered and tailored to specific stages in the lifecycle of a carbon sequestration site: active operation and injection, site closure, a 10 to 30 year period of post-closure monitoring and oversight, and finally long-term stewardship. $\frac{114}{4}$ The work of Alexandra Klass and Elizabeth Wilson is exemplary in this respect. They have advocated the following liability framework: $: 115$ First, during active operation and $\mathrm{CO}_{2}$ injection, the owner is liable for harm caused by site operations (the liability could derive from tort or statutory law), is required to hold adequate insurance, and is obliged to pay into a central fund for long-term stewardship of the site. ${ }^{116}$ Second, throughout the closure and post-closure period, the owner is responsible for site monitoring, verification, and any necessary remediation, is held liable for damages caused by $\mathrm{CO}_{2}$ releases, and is required to have financial backup in the form of bonds or insurance. $\stackrel{117}{ }$ Third, when a site enters long-term stewardship, all liabilities and responsibility for site oversight shift to the federal government. $\frac{118}{.}$

Resolving the appropriate set of policy instruments for the final stage (long-term stewardship) has proven to be particularly contentious. CCS industry leaders have singled out long-term liability as a major impediment to growth in the carbon sequestration industry. $\frac{119}{.}$ They claim that the uncertainty associated with long-term $* 22$ site liability creates an investment risk that makes CCS a non-starter. ${ }^{120}$ On the other side, critics of carbon sequestration and those concerned about the moral hazard created by relieving industry of liability have strongly opposed frameworks that transfer long-term site liability to the government. $\stackrel{.21}{ }$ Everyone, irrespective of their view about CCS, agrees that long-term site liability must be addressed one way or another.

We argue that little or no tension exists between long-term liability, which is presumed to provide incentives for industry to safely select and operate sequestration sites, and the environmentally sound development of geologic carbon sequestration. The reason, however, lies outside the existing debate because ex post tort liability is an ineffective deterrent for decisions that have impacts with long periods of latency. The conflict consequently disappears because little is lost when a company is relieved of long-term liability. Drawing on the technical details described above, it becomes clear that ex ante regulation is the single most important policy instrument for ensuring that latent impacts are factored into siting and operations decisions essential to the long-term safety of carbon sequestration sites.

The discussion that follows will focus on traditional principles of economic efficiency. We have framed the issues in this manner for two reasons. First, the objections being raised about moral hazard are based on conventional economic principles. Second, we take it as a given that environmentalists, particularly those who endorse the precautionary principle, will be sympathetic to subjecting sequestration sites to strict regulation and enhanced liability. The novelty of the technology, the potential for irreversible harm, and the anticipated scale of operations all reinforce this view. . $^{122}$ Those with a conservative economic perspective, by contrast, will be skeptical of such interventions. By drawing on economic arguments and particularly on a deterrence-based view of tort law, $\frac{123}{2}$ we are able to $* \mathbf{2 3}$ ground our case for a mixed system of regulation and liability on principles that can overcome these objections. 


\section{A. Regulation Versus Common Law Liability}

Whether common law tort liability and ex ante environmental regulation are substitutes for each other or complementary regimes has been hotly contested for decades. For a long time, orthodox economic theory considered them to be substitutes,

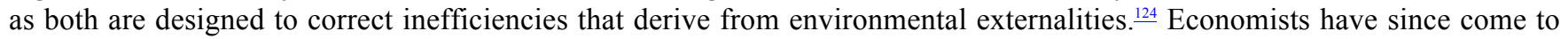
appreciate that structural features of ex post tort liability and ex ante regulation create important differences in how each system operates in practice, and that these differences produce opportunities for them to complement each other. $\frac{125}{1}$ Although still evolving, subsequent economic analyses have attempted to provide guidance on how tort liability and regulation can be effectively used in tandem. $\stackrel{126}{\underline{6}}$

Parallel use of tort liability and regulation, to varying degrees, has long been accepted by lawyers and policymakers. For public policies ranging from consumer products to industrial emissions, dual use of tort liability and regulation is more often the rule than the exception. $\stackrel{127}{ }$ Thus, while disagreement exists over many specifics, most legal academics recognize that regulatory agencies and common law courts play a complementary role in protecting public safety and the environment. .28

*24 Commentators have also recognized that harm-inducing activities exist on a continuum that ranges from discrete actions involving individualized harm (for example, the risk from chopping down a tree in one's yard) to mass torts involving thousands of claimants (for example, harms from air pollution or mass torts such as asbestos)..$\underline{129}$ It is now broadly accepted that the effectiveness of ex post tort liability relative to ex ante regulation varies dramatically across this spectrum of activities. $\frac{130}{\underline{10}}$

Propelled in part by the rise of mass torts in the 1980s, economists and lawyers began to arrive at a loose consensus on a set of structural features that distinguish the relative merits of tort liability and regulatory regimes. Steven Shavell, a leading economist writing in the area, was among the first to identify a set of governing criteria. He identified four primary factors: (1) knowledge asymmetries between the private sector and expert regulatory agencies, (2) capital constraints of liable corporate defendants, (3) likelihood that suits will be brought against liable defendants, and (4) administrative costs of implementing regulatory programs versus litigating tort suits. ${ }^{131}$ Shavell went on to describe subsidiary conditions that influence the impact of each of these factors, and thus whether tort liability is favored over regulation, or vice versa, or whether some combination of the two is likely to be most efficient. $\frac{132}{}$

\section{Shavell Framework}

Several broad patterns emerged from Shavell's analysis, as well as from the work of other commentators. $\stackrel{133}{\text { The impact of }}$ knowledge asymmetries, which were assumed to favor private interests due to their detailed knowledge of their facilities and processes, has figured prominently in this discourse. $\frac{134}{}$ But economists were forced to reassess this intuitive assumption when they realized that it could $* \mathbf{2 5}$ break down for health and safety regulations. ${ }^{135}$ It became evident that many businesses, especially smaller ones, have little knowledge about the environmental and human health effects of their operations. $\frac{136}{36}$ Accordingly, even if corporate officials have superior knowledge about reducing polluting emissions, their inability to assess the risks to the environment or human health creates a countervailing knowledge asymmetry that favors regulation over common law liability. $\frac{137}{}$ Knowledge asymmetries therefore often cut both ways, and their net effect can be difficult to predict.

Shavell's other factors have been less subject to revision. His insight about the impact of capital constraints is as vital as ever. The basic principle is simple: if a defendant's capacity to pay is less than the damages it could inflict, its capacity to pay will operate as a de facto cap on potential liability, and the incentive for due care created by tort liability will be inefficiently weak. ${ }^{138}$ Moreover, because the amount of a company's capital at stake will influence the cost of the insurance it purchases, insurance on its own will not offset these shortfalls. The effect of capital constraints can also create a perverse incentive for corporations to limit their exposure by spinning off the parts of their businesses vulnerable to large liabilities (such as mass torts) into small, low-capital companies. In general, the efficiency of ex post liability will decline the more potential liabilities exceed the capital reserves of a defendant. .39 
The likelihood that plaintiffs will file suit, if low, also erodes the effectiveness of tort liability, as it influences the probability that a defendant will be found liable. Two primary factors are important here: the degree to which harm is dispersed over a large number of people and the potential for substantial delay before a suit is filed. ${ }^{140}$ As a general rule, the probability of suit drops as the stake of any given person declines or the delay after which harm occurs grows.

The reasoning is again straightforward. If no plaintiff has a significant stake, no one will be motivated to incur the costs of bringing suit. Further, insofar as class actions are available to overcome the low stakes of individual plaintiffs, experience suggests $* \mathbf{2 6}$ that organizing a large group of plaintiffs can impede litigation, particularly if they have heterogeneous interests. ${ }^{141}$ Delay is problematic for plaintiffs because the evidence necessary to demonstrate who caused the harm and whether their actions were negligent will typically be more difficult to obtain. $\frac{142}{}$ Corporate executives will also discount the liability posed by distant suits based on the likelihood of suit and other factors discussed further below, thereby undermining the incentives provided by tort liability..$^{143}$

Administrative costs of tort liability and regulatory regimes are driven by different factors. The administrative costs of regulatory regimes for CCS would be high because of the complexity of technical rulemaking and because regulatory oversight would apply to all sites, regardless of whether or not they are operating safely. ${ }^{144}$ Conversely, tort regimes' costs scale with the number of claimants and the complexity of the harms; thus, the smaller the number of potential claimants and the simpler the technical issues, the more tort liability is favored. ${ }^{145}$ Roughly speaking, the balance will tip toward regulation with larger numbers of claimants and higher complexity because the cost savings of individualized rulings, which are triggered only when harm actually arises, are offset by the efficiency gained from generally applicable regulations.

Commentators have also identified other factors affecting administrative costs. These include the uncertainty of legal standards, which typically favors regulation; $\stackrel{146}{=}$ the confounding of harms attributable to background risks from other sources, such as exposure to background levels of cancer-causing chemicals $; \frac{147}{}$ and the challenges of clearly defining the potential class of victims, particularly in the case of mass tort actions where indirect impacts can become important. .48

The literature in this area is voluminous and still growing. Many variations on Shavell's initial framework have emerged that advocate $* \mathbf{2 7}$ different mixes of policies or identify circumstances in which specific forms of liability are favored over others or are superior to traditional regulation. Paul Calcott and Stephen Hutton, for example, have suggested that if regulatory oversight is error-free, then negligence-based liability combined with regulation is more efficient than strict liability. ${ }^{149}$ In a more recent analysis, Rouillon asserts that the use of regulation and tort liability "is always optimal" and that regulatory standards "should be designed in a less stringent manner when used jointly" with tort liability.

Much of this work is based on econometric studies subject to limiting assumptions that qualify the inferences one can draw from them. Accordingly, beyond the broad framework developed by Shavell, large uncertainties remain about how liability and regulatory regimes can be optimally combined.

\section{Private Versus Public Discounting of Latent Environmental Harms}

Economists commonly describe the principal objectives of a tort system as preventing accidents, compensating victims, and minimizing administrative costs. $\stackrel{151}{\text { The }}$ The objectives are frustrated when there is a long delay between the distribution of a product, harmful exposure, or decision triggering the risk of harm and the occurrence of harm:

When harmful exposure has occurred decades earlier, it is virtually impossible to achieve any meaningful preventive effect through the allocation of civil liability. There are insurmountable problems of discontinuity in enterprise management, unforeseeability of the parameters of risk, doubts about the contributory fault of others, speculativeness in discounting to present value ....

Put simply, the latency of harm can negate the incentives provided by a tort system. Incentives are further eroded when latent harms affect multiple victims and individual suits cannot be consolidated in a single class action suit. $\frac{153}{\text { In }}$ two such cases-harm to individuals living downwind of the Nevada nuclear weapons test site $* \mathbf{2 8}$ and victims of Agent Orange during the Vietnam war--the result was "staggering litigation costs and years of delay." 
The diminished incentives for corporate actors are particularly acute. As one commentator has noted, the "typical corporate decisionmaker . . . likely does not give much weight to the prospect of a liability judgment many decades into the future." This myopia is driven in large part by the difficulty of holding decision-makers accountable for latent risks, $\frac{156}{5}$ and by the short investment time horizon of senior managers that is reinforced by the arguably even shorter time horizon of shareholders in evaluating the profitability of firms. .57 As a consequence, even economically efficient decisions for future cost avoidance will lose against options with immediate effect, as executives will have nothing to show for the former. $\frac{158}{\cdot}$ Long latency periods can also produce perverse incentives for companies to operate with relative impunity and then go out of business, or alternatively to structure themselves into small, low-cap companies to limit their ultimate liability. $\frac{159}{9}$

A perfectly functioning market would preclude such divergences between a corporate actor's near-term interests and the long-term interests of the company, but this presumes that accurate information is available on latent risks, which often is not the case because risks may be inchoate (the problem of "unknown unknowns") until new information or understanding

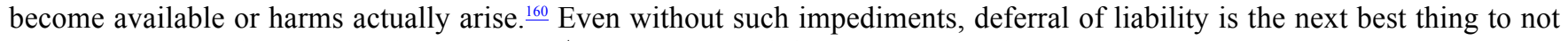
having to pay at all; to make this concrete, $\$ 1$ million of liability 40 years in the future has a net present value of just $* 29$ $\$ 452,890 . \stackrel{161}{ }$ Routine economic accounting of latent harm on its own causes the incentives provided by common law liability to be (perhaps rationally) discounted substantially.

The factors outlined above, among others, have led legal commentators to conclude that products or activities that produce harms with long latency periods negate the preventative effect of liability regimes and shift the primary goal of legal liability "to devising a low cost, equitable method of compensating victims." "드 Under these circumstances, no-fault liability schemes (such as the Price-Anderson Act for nuclear power reactors $\frac{163}{}$ and the Black Lung compensation system ${ }^{164}$ ) have a comparative advantage over traditional tort liability, but policymakers must be careful in designing them, as they too can be undermined by litigation. .65 The failure of common law regimes to deter latent harms also places a high premium on effective ex ante regulation, which is left as the primary means of deterring such harms. $\frac{166}{}$

More fundamental analytical problems arise when harms are latent for timescales of more than a few decades. Questions of intergenerational equity are important for timescales of this magnitude, and conventional methods of economic discounting become "speculative" and hotly contested. ${ }^{167}$ Liberal economists like Nicholas Stern maintain that social discount rates for *30 intergenerational impacts should be close to zero, as opposed to the market rates of seven percent advocated by more conservative economists. ${ }^{168}$ The important point for our purposes is that were the United States to adopt the Stern approach, private and public discount rates for the long-term risks associated with carbon sequestration would diverge dramatically. This divergence would undermine a liability regime because higher private discount rates would result in a societally inefficient (that is, low) level of deterrence for such long-term risks.

\section{B. Implications for the Debate over Long-Term Liability}

The preceding discussion describes the limits of tort liability as a legal mechanism for mitigating risky behavior and compensating victims. With respect to carbon sequestration, the Achilles' heel of tort liability is latency, which stands to be a significant, if not a dominant, characteristic of the risks associated with releases of $\mathrm{CO}_{2}$ or brine. However, unlike cases involving mass torts or many forms of environmental harms, the impediments posed by latency are less likely to derive from evidentiary gaps or scientific complexity. Particularly for site-selection decisions, neither information about the sequestered $\mathrm{CO}_{2}$ nor about causation will diminish over time. Nor, as we argue further below, should capital limits or the dispersed nature of the harms pose significant barriers. The limited effectiveness of liability will instead be driven by the near-term focus of corporate decision-making and potentially divergent private and public discount rates.

A perhaps Pyrrhic benefit of corporate myopia in this context is that it averts concerns that transferring responsibility for long-term liabilities from carbon sequestration sites to the government will compromise incentives that companies would otherwise have to safely select and operate their sites. Despite the abundance of attention that this putative conflict has received, the institutional limits of corporate accountability and the human psychology of latent harms negate the effectiveness of ex post liability regimes as an efficient deterrent for long-term risks. 
Only government regulation has the capacity to target risks with long latency periods. ${ }^{169}$ Yet, one must acknowledge that regulators are also subject to temporal myopia and political pressures that erode $* \mathbf{3 1}$ their willingness or ability to promulgate regulations that adequately consider long-term risks..$^{170}$ In contrast to most private entities, however, countervailing pressures from powerful organizations and individuals committed to environmental protection exist within and outside government. $\frac{171}{12}$ Differences also exist between the public and private sectors in their respective institutional norms, ranging from normative mandates to the appropriate discount rate, discussed above. Accordingly, and notwithstanding its own limitations, the government is institutionally better placed than the private sector to factor long-term risks into its decision-making processes. $\frac{172}{15}$

Contrary to concerns raised in debates over legal liability for releases of $\mathrm{CO}_{2}$ from sequestration sites, neither fears about unbounded long-term liability nor concerns about limiting it should be impediments to the safe deployment of geologic carbon sequestration. Instead, concerns about ensuring that carbon sequestrations sites are selected and operated with due care ought to be focused foremost on promulgating effective performance-based regulations.

\section{The Appropriate Forms and Limited Role of Tort Liability}

This section evaluates the circumstances under which traditional tort liability may provide meaningful deterrence against poor site selection and operation, as well as compensate victims when releases of brine or $\mathrm{CO}_{2}$ do occur. $\frac{173}{1}$ The analysis in the preceding section on the limitations of tort liability bounds the arguments made here: tort liability will play a secondary role to regulation. Our objective is briefly to analyze the tort doctrines available and specifically to determine whether enhanced forms of tort liability can offer an efficient means of mitigating near-term risks from carbon sequestration sites. Anticipating the arguments of opponents to enhanced liability, we begin by showing that there is little reason for $* 32$ concern that $\mathrm{CO}_{2}$ sequestration sites will be subject to the pathologies critics commonly associated with enhanced liability for environmental harms.

\section{A. Misplaced Fears About Liability for Releases from Sequestration Sites}

The legacies of Superfund, which governs liability for cleaning up contaminated property, and the more recent experience with a somewhat novel extension of tort liability to oil companies for the release of a gasoline additive (MTBE) from gas stations have overshadowed policy debates about CCS. We will distinguish the circumstances of each from the distinctive conditions relevant to carbon sequestration. It is relatively straightforward to show that the underlying bases for critics' concerns simply do not apply to carbon sequestration. With this case made, we then turn to the substantive analysis of the appropriate role for tort liability.

\section{The Long Shadow of Superfund Liability}

Decades of experience have shown that timely remediation of contaminated sites and compensation for damages to plaintiffs from environmental releases is enormously difficult to achieve. Superfund, which retroactively established strict, joint and several liability for releases of hazardous compounds into the environment, is viewed by its critics as exemplary of the pathologies endemic to enhanced tort liability for environmental harms. ${ }^{174}$ Yet, passage of Superfund was motivated by the salutary belief that "imposing a broad net of liability with a minimal causation requirement, limited defenses, and joint and several responsibility would encourage expeditious settlement of cases" and site cleanups. ${ }^{175}$ Thirty years after it became law, debate continues over the costs of implementing Superfund and its record of remediating contaminated sites.

Critics of Superfund believe, for a variety of reasons, that its objectives have been met only sporadically. Drawing on decades of data, they assert that cleanup of many sites was delayed by years and that disputes over liability and cost allocation led to an enormous amount of costly litigation. ${ }^{\frac{176}{6}}$ Some estimates suggest that the total $* 33$ public and private transaction costs associated with Superfund liability amount to between 24 and $44 \%$ of the direct costs of cleanup. $\frac{177}{\mathrm{~T}}$ These commentators maintain that the sheer magnitude of the liability (hundreds of millions of dollars at the largest sites) and the moral 
indignation of defendants at being held retroactively liable--jointly and severally no less--for decades-old releases caused an industry backlash that fueled Superfund litigation for years. $\stackrel{178}{-17}$

Even accepting these criticisms, which are hotly contested,,$\frac{179}{79}$ one must be careful in drawing inferences from experience under Superfund. This is particularly true for releases from sequestration sites because the conditions that complicated implementation of Superfund are largely absent. First, the imposition of enhanced liability would be prospective, thereby avoiding a primary source of the perceived unfairness of Superfund. Second, dramatic differences in the relative contributions of different parties are less likely to arise given the infrastructure costs and benefits of scale for sequestering $\mathrm{CO}_{2}$, as most if not all sequestration sites will be large and thus of similar scale. ${ }^{180}$ Third, and perhaps most important, releases from sequestration reservoirs will involve only two substances, brine or $\mathrm{CO}_{2}$, and the amount of $\mathrm{CO}_{2}$ sequestered will be closely monitored and independently verified. $\frac{181}{}$ Both of these factors will greatly simplify liability suits and, if joint and several liability were to apply, contribution actions between defendants. Fourth, because the damages caused by leakage of $\mathrm{CO}_{2}$ are projected to be modest and information about relative contributions difficult to contest, $\frac{182}{2}$ quick settlements should be the norm. Each of these factors militates against the pathologies that critics associate with Superfund.

Critics also raise the specter that imposing enhanced liability could cause corporations to employ strategic responses to mitigate their liability. Such second-order strategic responses often involve *34 companies spinning-off or outsourcing highrisk activities to smaller entities as a means of effectively capping or circumventing liability. $\frac{183}{\text { The limited resources and }}$ diminished exposure of smaller companies can in turn cause them to underinvest in risk-management capabilities and technical resources, effectively nullifying the expected benefits of strict liability. More troubling, the net effect of imposing strict liability could be negative, with environmental releases actually increasing under a strict liability regime, $\stackrel{184}{a}$ although these claims are also contested. $\frac{185}{1}$

In any case, the economics of geologic sequestration ought to preclude such corporate gerrymandering. The benefits of scale raise the costs of limiting liability in this manner while the modest risks lower the liabilities at stake; both disfavor this type of strategic behavior. Although we expect it will be unnecessary, policymakers (and ultimately judges) may nevertheless want to protect against such tactics. Borrowing from Superfund, this could be achieved by extending liability to upstream generators of $\mathrm{CO}_{2}$, which would give them an additional incentive to select reputable companies and to demand transparent accounting of sequestration operations.

\section{Misreading the Implications of the MTBE Controversy}

Tort liability is controversial in many settings, and liability for environmental harm beyond Superfund has also inspired industry cynicism and scorn. The most recent high-visibility incident involved the release of the gasoline additive methyltertiary butyl ether (MTBE) from poorly maintained underground storage tanks into drinking water aquifers. $\frac{186}{}$ MTBE has been frequently singled out as a cautionary story that illustrates the dangers of tort liability for geologic sequestration of $\mathrm{CO}_{2} \cdot \frac{187}{}$ MTBE was certified by the EPA in the early 1990 s to mitigate vehicle emissions and subsequently used *35 widely throughout the United States. $\frac{188}{}$ Unfortunately, by the late 1990s MTBE was discovered in many public water supplies and identified as a suspected human carcinogen. $\frac{189}{}$ Much class-action litigation ensued..$\underline{190}$

The lawsuits were not, however, brought against the gas stations from which MTBE had leaked. Instead, the plaintiffs' attorneys targeted large oil companies, which were far fewer in number and had the capital to cover the remediation costs and damages. .191 The plaintiffs claimed that the oil companies had negligently distributed gasoline containing MTBE with prior knowledge of its environmental risks. ${ }^{192}$ To the surprise of many critics, the plaintiffs' strategy was successful despite evidentiary challenges in establishing liability (MTBE spread widely and rapidly underground). Those challenges were overcome by imposing proportional liability based on each company's market share. ${ }^{193}$ Needless to say, this did not sit well with the industry, which viewed the targeting of oil companies as unfair because they were not directly responsible for the releases of MTBE and, perhaps more infuriatingly, because the EPA had sanctioned the use of MTBE in gasoline. ${ }^{194}$

Many legal commentators view the MTBE saga in a very different and much rosier light. They maintain that the plaintiffs' success demonstrates the flexibility of tort law and its capacity to correct regulatory failures. ${ }^{195}$ According to this perspective, courts were justified in extending liability to the oil companies for two reasons. First, the oil companies had both sufficient 
financial resources and the capacity to broadly spread the costs of the liability, whereas the victims had neither. $\frac{196}{}$ Second, extending liability to the $* \mathbf{3 6}$ oil companies created an incentive for them to ensure that the small entities selling their products are safely operated and adequately insured.

Whatever one's view of the MTBE litigation, leakage of brine or $\mathrm{CO}_{2}$ from geologic sequestration sites is unlikely to trigger a similar controversy. Perhaps most importantly, it is doubtful that carbon sequestration sites will be either owned by small entities or cause economically ruinous damage. As we have shown, the technical complexities, regulatory demands, infrastructure costs, and scale of individual sites all cut against an industry structure mirroring that of the oil industry (that is, large corporate producers and refiners upstream and small, low-capital businesses at the retail level). $\frac{197}{}$ The potential harms will also be less widespread and costly.

Finally, given the technical limits of site characterization methods and the recognition among experts that some degree of

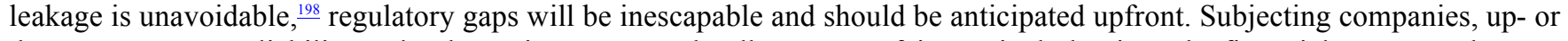
downstream, to tort liability under these circumstances hardly seems unfair, particularly given the financial resources they are likely to have, the availability of insurance coverage, and the capacity of large companies operating in a national-level (if not international) industry to spread costs.

\section{B. Comparative Advantages of Different Forms of Tort Liability}

$\mathrm{CO}_{2}$ releases from sequestration sites could be subject to any one of the three basic forms of tort liability: negligence, nuisance, or trespass. Each doctrine has a particular orientation. Negligence, as the term implies, addresses negligent acts of defendants who owe a duty of care to a plaintiff. Nuisance centers on actions by a defendant that interfere with a plaintiff's "use and enjoyment" of her land, while trespass is triggered when a defendant causes a physical intrusion on a plaintiff's land. The operator of a carbon sequestration site, for example, could negligently cause $\mathrm{CO}_{2}$ to leak into an overlying aquifer on neighboring properties and severely degrade the water quality, thereby implicating all three tort doctrines.

\section{*37 1. Negligence: Due Care and Causation}

A defendant's conduct will be deemed negligent if it causes harm to a plaintiff and does not meet the applicable duty of care established by statute or professional norms. .999 The relevant conduct for our purposes encompasses the selection, operation, and closure of a sequestration site. Courts apply several subsidiary tests for reasonableness of care, including whether the harm was foreseeable and, if so, whether the precautions taken were a "reasonable" response to the risks at stake; defendants need not eliminate risk altogether..$^{200}$ In complex cases involving harm to human health and the environment, causation often becomes a limiting element for plaintiffs because it is difficult to prove. ${ }^{201}$ A countervailing virtue of negligence is that it can be used by plaintiffs who are injured personally by leakage of $\mathrm{CO}_{2}$ but whose land is unaffected (for example, users of public water systems).

The most significant risk associated with releases of brine or $\mathrm{CO}_{2}$ from sequestration sites--contamination of drinking water aquifers--is likely to make it difficult for plaintiffs to show that a defendant failed to exercise "reasonable care" and to establish causation. The standard of due care for site selection, which is the single most important decision for site performance,,$\frac{202}{0}$ would have to be defined at a general level despite the heterogeneity of sites and the tradeoffs in site characterization methods caused by inherent technical and practical limits discussed further below. $\frac{203}{}$ This analysis would require courts to balance the potential for site characterization to increase risks (site characterization typically requires drilling additional wells into a reservoir) against the benefits of additional information. Similarly, operational decisions will often be highly dependent on technically complex site-specific circumstances that may involve difficult tradeoffs.

Establishing negligence will be further complicated if multiple defendants inject $\mathrm{CO}_{2}$ into the same brine reservoir but no single defendant injects more than a small fraction of the total. Absent *38 application of enhanced liability (proportional or strict), ${ }^{204}$ a plaintiff would have difficulty establishing causation, as no single defendant may have contributed "substantially" to the resulting harm. .25 


\section{Relative Strengths of Trespass and Nuisance}

The doctrines of trespass and nuisance require showing that a defendant's activity has encroached on a plaintiff's property rights. Trespass involves an intentional, reckless, or negligent act that interferes with a plaintiff's "possession" of her land. Intent may be established if a trespass is "substantially certain" to follow from a defendant's action, regardless of whether the trespass was intentional. .07 For CCS, the migration of $\mathrm{CO}_{2}$ and brine is "substantially certain" to occur (estimates of subsurface storage capacity are in fact premised upon occurrence of significant migration) and will be the subject of extensive modeling at each site..$^{208}$ The intentionality requirement for trespass should therefore be straightforward for plaintiffs to establish.

Nuisance involves an interference with a plaintiff's "use and enjoyment" of her land. ${ }^{209}$ The primary difference between trespass and nuisance is that trespass requires a direct physical invasion of a plaintiff's property, whereas nuisance does not. For example, intrusion of $\mathrm{CO}_{2}$ into the subsurface of a plaintiff's property could constitute a trespass,,$\frac{210}{}$ and if the intrusion interferes with the use of a plaintiff's property (for example, by degrading water quality in a well), it could also constitute a nuisance. .11 In general, neither doctrine requires that the defendant have a duty to use due care or that the defendant have acted negligently. Thus, whereas negligence involves liability-forming conduct, trespass and nuisance involve liabilityproducing conditions.

*39 The standards that apply under trespass and nuisance differ in several important respects. The standard for nuisance turns on whether a defendant has caused an unreasonable interference with a plaintiff's foreseeable use and enjoyment of his property. $\stackrel{212}{ }$ Similar to negligence, courts balance the utility of a defendant's conduct against the harms to a plaintiff in determining whether a nuisance exists, and this risk-benefit balancing is central to a court's judgment. $\frac{213}{}$ Other factors may also enter into the analysis, such as the duration of the interference; a nuisance will likely be found for persistent interferences even if the degree of interference is minor. .14 Actions for nuisance, public or private, would cover direct damages to property from releases of brine or $\mathrm{CO}_{2} .{ }^{215}$

Trespass turns on whether a defendant's actions have caused a substance to intrude onto a plaintiff's land. ${ }^{216}$ However, when a trespass occurs in the subsurface of a plaintiff's property, trespass often becomes a special case of the nuisance doctrine, as many jurisdictions require that a subsurface trespass cause some kind of physical damage or interference with the use of the property in question..$^{217}$ Commentators have also suggested that the technical challenges may make it difficult for plaintiffs to establish proof of subsurface trespass. $\frac{218}{}$ Accordingly, absent proof of some form of interference with a foreseeable use of a plaintiff's property, trespass claims will be foreclosed.

As applied to releases of $\mathrm{CO}_{2}$ from sequestration sites, nuisance and trespass have two important advantages for plaintiffs over negligence. First, because neither trespass nor nuisance claims stemming from migration of $\mathrm{CO}_{2}$ or brine will be premised on negligent conduct, the fact that a defendant was meeting the conditions of a valid state or federal permit is largely irrelevant. The existence of a valid permit can enter a court's nuisance analysis only * $\mathbf{4 0}$ indirectly when it balances the utility of a defendant's conduct against the harm to the plaintiff. $\stackrel{219}{ }$ By contrast, while compliance with a permit is not determinative in a negligence case, it is directly relevant to determining whether a defendant exercised due care. ${ }^{220}$ Second, in suits that arise long after the relevant conduct has occurred or decisions have been made, trespass and nuisance claims will be less impacted than negligence claims because they focus on current conditions rather than a defendant's earlier conduct.

Application of the two doctrines will be more complicated for releases of brine. While the benefits of bringing a nuisance claim for brine intrusion are identical to those for $\mathrm{CO}_{2}$, it is uncertain whether a claim of trespass will be viable. The reason for this is that either there will be no physical trespass of brine from a defendant's property, or insofar as there is a trespass, it will be impossible to trace. $\frac{221}{1}$ In the latter case, the limited case law that exists suggests that trespass claims will be precluded unless a plaintiff can demonstrate direct and measurable damages to his property. .22

\section{The Merits of Enhanced Tort Liability}

Three supplementary tort doctrines--strict liability, proportional liability, and joint and several liability--have the potential to 
mitigate the challenges of establishing liability for harmful releases from sequestration sites. Strict liability eliminates the need to demonstrate negligence, proportional liability relaxes the standard for demonstrating causation under a theory of negligence, and joint and several liability makes defendants individually and collectively liable *41 for the harms at issue regardless of their respective contributions. These doctrines increase both the likelihood that a plaintiff will prevail and the potential liability of defendants, and in so doing, enhance the incentives for defendants to mitigate risks.

\section{The Basic Forms of Enhanced Liability Relevant to Environmental Harms}

For environmental harms, strict liability is triggered when a defendant owns or operates a facility from which a harmful substance was released regardless of whether the defendant was negligent. ${ }^{223}$ Strict liability is most commonly applied when products or activities are deemed to be "abnormally dangerous." create a significant risk of physical harm. $\frac{225}{2}$ Economists justify this condition on the ground that strict liability should apply to activities posing risks that cannot be mitigated through due care. $\underline{26}$ Strict liability thus complements negligence; it applies when a standard of due care is insufficient to mitigate the risks posed by an activity. $\frac{227}{}$ Under this theory, strict liability provides incentives for more radical forms of risk mitigation, such as relocating or downscaling a dangerous activity. $\underline{228}$ It promotes these changes by increasing the effective liability, costs of capital, and insurance coverage. $\underline{229}$

While strict liability is generally disfavored in the United States, cases involving environmental contamination are among the few exceptions to this general rule. $\frac{230}{}$ In New Jersey, for example, several cases involving environmental contamination have held defendants strictly liable when they were unaware that the materials released from their facilities contained toxic chemicals..$^{231}$ Because no cases have been filed to date that allege liability for environmental releases $* \mathbf{4 2}$ of $\mathrm{CO}_{2}$ from injection operations (primarily the use of $\mathrm{CO}_{2}$ to enhance oil recovery), it is unclear whether geologic sequestration of $\mathrm{CO}_{2}$ will trigger strict liability. $\frac{232}{2}$

Proportional liability is a variant of negligence that is applied even more sparingly than strict liability. $\frac{233}{\text { It }}$ was designed to address circumstances in which contributions to a source or type of harm are indivisible (for example, a toxic chemical spill with multiple, undifferentiated contributors). ${ }^{234}$ The doctrine lowers the effective standard for causation (a plaintiff merely has to demonstrate that a defendant contributed to the source of harm), and ultimate liability is based on a defendant's relative contribution to an otherwise indivisible source of harm..$^{235}$ Unless defendants are able to produce direct evidence of their relative contribution, courts use surrogate metrics, such as market share or volumetric contribution, to calculate the proportion of the damages for which a defendant will be liable. $\underline{\underline{236}}$

Courts typically limit the application of proportional liability to circumstances in which defendants have contributed to the same or very similar sources of harm (for example, all sold the same product suffering from the same defect). $\frac{237}{}$ This requirement should not preclude claims based on proportional liability for releases from sequestration sites, as potential defendants will all be injecting the same substance and causing identical types of harm.

Joint and several liability increases the potential scope of liability for all defendants by making them collectively and individually responsible for all of the harms associated with an environmental release to which they have contributed. $\frac{238}{.}$ This approach enables plaintiffs to seek compensation from a single, wealthy defendant and thereby to reduce litigation costs and delays in receiving compensation. Equity and fairness are factored into the doctrine by allowing defendants to seek compensation from responsible parties who were not sued by the plaintiff. ${ }^{239}$ State-level statutory and $* \mathbf{4 3}$ common law reforms have created a patchwork of approaches to joint and several liability. Although twenty or so states have retained the doctrine-- largely by failing to legislate restrictions--it is rarely applied in practice,,$\frac{240}{2}$ and many states have passed laws that greatly limit its applicability..$^{241}$ Accordingly, absent specific state or federal legislation, joint and several liability is unlikely to be available.

\section{Subjecting Sequestration Sites to Enhanced Liability: Unilateral Harms}

The standard justifications for strict liability do not apply to $\mathrm{CO}_{2}$ sequestration sites. Strict liability is conventionally justified as a gap filler when abnormally dangerous activities cannot be mitigated through the exercise of due care. $\frac{242}{}$ Yet, one of our central arguments is that releases of either brine or $\mathrm{CO}_{2}$ from sequestration sites are unlikely to pose large risks, from which 
one can infer that sequestration of $\mathrm{CO}_{2}$ is not an abnormally hazardous activity that warrants imposition of strict liability. The unique characteristics of geologic sequestration of $\mathrm{CO}_{2}$ also limit opportunities to downscale or fundamentally change injection processes. Indeed, to the extent that sequestration of $\mathrm{CO}_{2}$ is effective, it would occur on an extraordinarily large scale,, 43 and it is precisely this enormous capacity to mitigate $\mathrm{CO}_{2}$ emissions that makes CCS an attractive option. Economies of scale and the vastness of saline reservoirs further cut against reducing the size of individual sequestration sites,,$\frac{244}{}$ as it would limit the rate at which $\mathrm{CO}_{2}$ could be injected and dramatically reduce the amount that could be sequestered.

These justifications overlook an often underappreciated alternative factor--the unilateral nature of the risks. In this context, a unilateral harm would be one solely within the control of site operators. ${ }^{245}$ The concept of unilateral harm clearly applies to $\mathrm{CO}_{2}$ sequestration because injured parties would be passive receptors of the harms from leakage of $\mathrm{CO}_{2}$ or brine. Subjecting sequestration sites to strict liability under these circumstances is economically $* \mathbf{4 4}$ efficient because site operators--through siting, operational, and closure decisions--are the only parties capable of mitigating risks, and are thus by definition the lowest-cost risk avoiders. $\frac{246}{6}$

This argument does not necessarily rule out negligence, which can produce economically efficient outcomes for unilateral risks if courts set due care at the socially optimal level. ${ }^{247}$ However, resolving the level of due care is likely to be challenging for courts given the limits of careful site characterization to detect certain leakage pathways, ${ }^{248}$ the diminishing returns of increasing the resolution of site assessments (as well as monitoring), and the risks associated with site characterization methods (requiring drilling additional test wells). ${ }^{249}$ In short, persistent technical uncertainties, which will vary markedly between sites, will cloud efforts by courts to establish a clear standard of due care. Where such uncertainty prevails, economic principles favor strict liability over negligence. $\frac{250}{5}$

The relative simplicity of establishing strict liability will also lower litigation costs relative to a negligence regime. Lowering the cost of litigation and enhancing the likelihood of prevailing through strict liability would also increase the number of suits, thereby potentially increasing aggregate administrative costs. $\frac{251}{5}$ However, this inference ignores the potential for settlement rates to increase, which seems quite likely in this context. Recall that the volumes of $\mathrm{CO}_{2}$ sequestered will be precisely tracked, ${ }^{252}$ and this information would suffice to decisively establish causation under strict liability and to provide a basis for allocating liability between defendants. Collectively, these considerations suggest that the net impact on administrative costs will likely favor strict liability over negligence or will at worst be a wash.

Liability, even for modest risks, still has the potential to impact site-selection decisions. ${ }^{253}$ Rough estimates of sequestration capacities $* \mathbf{4 5}$ in the United States suggest that, at least in the near-term, many high-quality sites will be available. $\frac{254}{\text { This }}$ surplus should continue during the early period of CCS deployment when experience is being gained rapidly. The availability of multiple potential sites suggests that liability, particularly strict liability, can be used to encourage facility owners to locate sequestration sites in low-risk regions. If geologic sequestration of $\mathrm{CO}_{2}$ is successful, cost-premiums will increase for higherquality sites, but by that time scientists may have a better understanding of harmful releases and perhaps improved methods for mitigating them, and this information could be integrated into formal siting and site-operation regulations. Tort liability is therefore likely to be most effective during the earlier stages of CCS deployment.

The applicability of proportional liability, which requires a showing of negligence, will be limited to circumstances under which either (1) subsurface $\mathrm{CO}_{2}$ plumes overlap and are a source of leakage, or (2) zones of elevated pressure around injections wells interact such that reservoir pressures at a point of leakage (such as an abandoned well) are driven by them collectively. As we have seen, the latter case is both much more probable, given the huge projected areas of elevated pressure, and is likely to arise much earlier..$^{255}$ Although plaintiffs rarely succeed in convincing courts to invoke proportional liability, the detailed information that will be available on injection volumes of $\mathrm{CO}_{2}$ and the identical nature of the contributions from injection sites--each injecting only $\mathrm{CO}_{2}$ and all driving pressure increases-- make this an ideal case for proportional liability. Insofar as negligence is viewed as the appropriate legal regime, proportional liability will be indispensable.

The case for imposing joint and several liability is by far the weakest. Unlike many of the contaminated sites covered by Superfund, the number of potential defendants should be tractable given the scale of the operations, the potential for defendants to be judgment-proof (whether through bankruptcy or low capitalization) will be low, and the magnitude of the 
likely impacts will be modest. Under these circumstances, the potential for over-deterrence, which naturally arises when the scope of liability is expanded beyond what a given defendant is responsible for, is likely to outweigh the benefits to *46 plaintiffs. Neither the number of potential defendants nor the challenges of identifying them is likely to limit plaintiffs' ability to file a suit.

An important caveat must be kept in mind: like all other forms of ex post liability, the incentives created by enhanced forms of liability will depend on the timing of $\mathrm{CO}_{2}$ or brine leakage. For reasons discussed above, ${ }^{256}$ if releases largely occur after a significant latency period (decades after active injection of $\mathrm{CO}_{2}$ ceases), enhanced liability will have only very modest deterrence value. Insofar as enhanced liability targets relatively near-term risks, it can be a useful complement to traditional regulatory requirements. The degree to which this holds may be mitigated by the uncertainties about the timing of site leakage, but rigorous regulatory standards will be necessary regardless of the liability regime put in place.

\section{The Appropriate Role of Tort Liability}

Commentators have focused significant attention on how enhanced liability could be applied to sequestration sites. Alexandra Klass and Elizabeth Wilson have suggested that application of strict liability will vary from state to state. ${ }^{257}$ They predict that strict liability would not be applied in states like Texas, where $\mathrm{CO}_{2}$ is used routinely in enhanced oil recovery, but could be applied in Eastern or Midwestern states where it remains a novelty. ${ }_{258} \mathrm{John}$ Moore has expressed concern about scenarios in which leakage of $\mathrm{CO}_{2}$ poses much greater risks than currently predicted. $\stackrel{259}{ } \mathrm{He}$ raises the specter of a mass-tort scenario in which "owners and operators of . . f facilities could potentially be liable to a large number of claimants ... within tens or hundreds of kilometers of injection sites." ${ }^{.260}$ His concern rests on the potential breadth of harm and the low barrier to suit created by strict liability. $\underline{261}$

Surprisingly, debate over the applicability of enhanced liability has tended to avoid normative theories such as those discussed above. Moore's concern that large numbers of plaintiffs could potentially file $* \mathbf{4 7}$ suit comes closest, but the scenario itself is highly speculative, and he does not ground his argument on economic principles. The CCS industry's hostility to enhanced liability is also based on speculative scenarios of debilitating liability. $\frac{262}{2}$ In the opposing camp, Klass and Wilson have asserted that neither strict liability nor joint and several liability should be rejected out of hand, and articulated mild support for a specialized law establishing enhanced liability for releases $\mathrm{Cf}_{2}$ from sequestration sites. ${ }^{263}$ Citing some of the principles discussed above, they base these claims on the belief that enhanced liability would enable plaintiffs injured by a $\mathrm{CO}_{2}$ leak to obtain funding for remediation actions and compensation for damages. ${ }^{264}$

These theoretical gaps have been compounded by the abstract treatment of the risks at stake. The timing of potential harms is, as we have seen, central to the effectiveness of tort liability, and timing turns on the nature of a release and the technical capacities to detect it. Subsurface monitoring can identify leakage from a sequestration reservoir long before impacts on risk receptors arise, and thus before legally cognizable harms exist. ${ }^{265}$ Surface or near-subsurface monitoring can detect direct impacts on drinking water quality, but scientists believe that such releases would not be detectable "at a well-designed storage site in the foreseeable future" (with only very small and slow leakage points). ${ }^{266}$ Moreover, extended periods of latency (beyond the operational phase of a site) could foreclose most avenues for altering site operation--apart from the drastic option of removing stored $\mathrm{CO}_{2}$--and limit options to near-surface remediation or natural attenuation. In any event, latency would also greatly diminish the deterrence value of tort liability.

The best cases from a liability standpoint will involve relatively near-term releases (during site operation or closure) with readily detectable impacts. The only realistic candidates will involve releases of brine or $\mathrm{CO}_{2}$ through significant transmissive faults or abandoned $* \mathbf{4 8}$ wells. $\frac{267}{}$ These types of releases have been singled out by numerous scientists as the most important source of risk from sequestration sites, but in the case of faults, they can also be the most difficult to identify during site characterization. ${ }^{268}$ Both the early timing and elusiveness of these risks play to the strengths of ex post liability, ${ }^{269}$ and thus make them ideal test cases for comparing the relative virtues of different forms of liability.

\section{The Net Effect of Imposing Enhanced Liability}


The case for enhanced liability is strong but requires a nuanced understanding of the circumstances under which harmful leakage from a sequestration site is likely to occur. The current debate largely sidesteps the factual details and economic grounds on which liability regimes are conventionally evaluated. As discussed above, we believe that the single most important factor favoring enhanced liability is the unilateral nature of the harms; site operators are the least-cost avoiders because only they have the capacity to prevent or mitigate harm. However, the practical value of enhanced liability cannot be assessed without considering the overlapping standards of conventional tort doctrines of nuisance and trespass. Recall that while neither nuisance nor trespass claims will require a showing of negligence, trespass is essentially a strict liability doctrine, whereas nuisance requires the court to balance the utilities of the opposing parties. In either case, the net effect of imposing strict liability cannot be evaluated without considering the applicability of these other tort doctrines.

Relative to negligence, strict liability increases the likelihood that plaintiffs will prevail and thus file suit. To varying degrees, the same can be said of trespass and nuisance. The applicability of these doctrines will turn on plaintiffs showing that a defendant has interfered with a property right--a requirement which large releases of $\mathrm{CO}_{2}$ or brine into a drinking water aquifer could meet. Depending on the magnitude of the impacts, the balancing of the utilities $* 49$ required under nuisance could also favor plaintiffs, given that reasonable measures should be available to avoid or mitigate harms (for example, reduce injection rates, plug a leaking well, or treat affected water sources). ${ }^{270}$ Under these circumstances, the application of strict liability and trespass will track each other, while the balancing required under nuisance adds a layer of analytical uncertainty.

These doctrinal similarities suggest that for near-term releases involving a single defendant, strict liability would not increase the plaintiffs' odds of success over trespass claims and may not be markedly superior to nuisance. One must nevertheless be careful to consider the distinct conditions under which releases of $\mathrm{CO}_{2}$ and brine can occur. For a single injector, the source of a $\mathrm{CO}_{2}$ release will be easily traceable and will necessarily involve a trespass, implying that all three doctrines will apply. Releases of brine, however, will be triggered by elevated pressures, which could extend miles from the injection well. ${ }^{271}$ At these distances, no plausible basis will exist for claiming that brine from a defendant's property has trespassed onto a plaintiff's property because actual physical movement of brine is projected to occur on the order of feet, not miles. ${ }^{272}$ This result implies that plaintiffs will rarely be able to bring a claim for trespass.

The rough parity in deterrence provided by strict liability and standard forms of liability will be broken further when multiple parties sequester $\mathrm{CO}_{2}$ in the same deep saline reservoir. Recent scientific modeling has found that zones of elevated pressure around injection wells are likely to interact within years to decades, at which point it will be impossible to separate the contributions from each well to pressure buildup in a reservoir. $\frac{273}{}$ Moreover, although the specific timing will depend on the distances between injection wells, model results suggest that wells spaced tens of kilometers apart will interact within a few years. ${ }^{274}$ By contrast, the model results were just $* \mathbf{5 0}$ the opposite for $\mathrm{CO}_{2}$ plumes, which were projected to remain relatively localized and thus unlikely to overlap..$\underline{.75}$

To date, it has been the potential indivisibility of $\mathrm{CO}_{2}$ plumes from different injection wells that has often animated calls for applying enhanced forms of liability to sequestration sites. Strict liability would circumvent the problem by defining causation broadly (as contributing to $\mathrm{CO}_{2}$ injections into a reservoir). Proportional liability would redefine causation in a similar manner, but it would also require plaintiffs to demonstrate that each defendant acted negligently. Under this approach, joint and several liability would reduce litigation costs and delays by enabling plaintiffs to sue a single party for the total damages..$^{276}$ Both strict liability and strict, joint and several liability would increase the likelihood of plaintiffs successfully bringing suit relative to proportional liability.

The net benefits of the different doctrines will clearly differ depending on whether a release involves $\mathrm{CO}_{2}$ or brine. Harmful releases of $\mathrm{CO}_{2}$ will be subject to strict liability under the doctrine of trespass irrespective of whether enhanced forms of liability are available because $\mathrm{CO}_{2}$ plumes from different injection wells are unlikely to overlap. Subjecting these types of releases to enhanced liability is therefore unlikely to have any effect. On the other hand, pressure-driven releases of brine will rarely entail a trespass, and where multiple parties are involved, the pressure effects driving a release will not be attributable to a single injector. This result suggests that accountability for such releases will typically be foreclosed absent enhanced liability. Put differently, the motivation for applying strict liability to sequestration sites ought to rest solely on the potential risks associated with releases of brine. 


\section{Negligence Versus Strict Liability}

A critical factor in deciding between negligence and strict liability is the likelihood that courts will establish an efficient level of due care. In general, to the extent that determining the level of due care is technically complex and site-specific, strict liability will be favored over negligence or proportional liability. .777 Strict liability in essence transfers judgments about due care from the courts to $* \mathbf{5 1}$ defendants, who are presumed to possess the information and requisite knowledge to evaluate risks and benefits. We have already argued that the limits of geological data and the heterogeneity of site characteristics favor imposition of strict liability. ${ }_{278}$ But these factors are most relevant to ex ante site selection, which differs in substance and information content from operational decisions.

This distinction is important because the incentives provided by liability are quite different at the site selection and operational phases of a sequestration project. The differences can be appreciated by considering them separately. Focusing first on site selection, there would be no added value in imposing strict liability on the best class of sites, as such sites would already be in optimal locations. By contrast, applying strict liability to low-quality sites could deter companies from selecting them based on attributes other than safety. Accordingly, to the extent that sites can be ranked (even roughly) upfront, efficiency could be enhanced by tiering the form of liability based upon the ranking of a sequestration site: negligence for the best sites, and strict liability for lower-quality sites.

In practice, site selection will not be determinative of risk, although it is generally viewed as a site operator's single most important choice regarding safety. Operational decisions (such as monitoring systems and protocols) are important because they can facilitate identification of releases and mitigate their impacts. This will be true of even the best sites because certain key variables (for example, reservoir permeability) cannot be resolved at the site selection stage. ${ }^{279}$ Further, at the operational stage the exercise of due care is less affected by the information gaps that exist when a site is selected, as a substantial amount of additional information is generated once a site is running. $\frac{280}{2}$

This qualitative analysis suggests that negligence can provide an efficient level of deterrence against operational risks, assuming of course that courts can set the level of due care efficiently. If true, this would also support a tiered system of liability. For the best sites, liability would be directed solely at operational risks, for which negligence may suffice. For lower-quality sites, strict liability would $* \mathbf{5 2}$ promote proper site selection, but this decision also implicates operational decisions because the nature and magnitude of a site's risks will be a function of both site selection and operational decisions, as will the quality of the information available (better sites will typically be easier to monitor). Accordingly, because operational decisions are more complicated for poorer sites, it makes sense to subject them to strict liability as well.

It is worth noting that the relative value of liability may increase for operational decisions. Information asymmetries between site operators and regulators are likely to increase because significant new information is generated during the $\mathrm{CO}_{2}$ injection process.$\stackrel{281}{.}$ Yet, resource constraints will limit the EPA's capacity to scrutinize this new data and knowledge,, 282 much of which will be relevant to assessing risks. $\frac{283}{3}$ The information generated will also be highly site-specific, thereby limiting the benefits of scale that can enhance the relative efficiency of regulatory programs. ${ }^{284}$ For the types of near-term risks implicated here, the likely emergence of information asymmetries reinforces the potential for tort liability to complement traditional regulatory regimes based on uniform minimum standards.

Synthesizing our findings leads to the following conclusions. First, absent legislative intervention, releases of $\mathrm{CO}_{2}$ will be subject to strict liability through trespass. Second, some form of enhanced liability (strict or proportional) should apply to releases of brine to overcome the indivisibility problems that could otherwise preclude plaintiffs from successfully bringing claims under either negligence or nuisance. Third, the deterrence value of liability--whatever its form--will be limited to the relatively near-term risks associated with releases through faults or abandoned wells. These findings reveal that the current debate over regulation of sequestration sites ignores the primary source of risk--brine intrusion--and misapprehends the legal *53 issues in both the short and the long term. In particular, the debate has overstated the potential role of tort liability as a policy instrument for promoting safe sequestration of $\mathrm{CO}_{2}$ and the importance of liability in mitigating long-term risks.

The preceding discussion provides a theoretically grounded model for enabling liability to complement regulations more 
effectively. We have shown that a strong case exists for extending strict liability to all sites for releases of $\mathrm{CO}_{2}$ and brine: the harms are unilateral, and it will be challenging for courts to set an efficient level of due care. However, the political opposition to subjecting sequestration sites to strict liability is likely to preclude this approach, as is the judicial trend against imposing strict liability. Conventional principles of economic efficiency also support selective extension of strict liability if courts can set efficient levels of care for operational decisions, which the higher-quality information available for low-risk sites ought to facilitate. Under this two-tiered framework, strict liability would apply to lower-quality sites (such as sites with poor cap rock or valuable overlying aquifers), while negligence or proportional liability or both would apply to high-quality sites for releases of brine (trespass will cover harm from releases of $\mathrm{CO}_{2}$ from all sites).

This system would supplement a traditional ex ante regulatory regime, which is itself vulnerable to substantial informational gaps and asymmetries, by providing an added (albeit limited) incentive for site owners to select higher-quality sequestration sites. This pragmatic approach attempts to balance the twin virtues of efficiency and political viability without sacrificing the primary benefits of the former in favor of the latter. Nevertheless, because this approach would require new legislation (perhaps an amendment to the Safe Drinking Water Act (SDWA) ${ }^{285}$ ), we should also assess alternative purely regulatory approaches. As described further below, we expect political opposition to rigorous oversight to be substantial, whatever form it takes. We propose this hybrid approach both because it is normatively grounded on conservative economic principles and because we believe it has political virtues that could mitigate industry opposition.

\section{*54 IV. A Two-Tiered System of Liability and Minimum Performance-Based Standards}

In this final section, we further describe our hybrid policy framework for geologic sequestration of $\mathrm{CO}_{2}$ that exploits the complementary strengths of common law liability and traditional regulation. The framework uses enhanced liability in conjunction with regulatory standards and data: sites below a specified safety ranking would be subject to strict liability and possibly heightened regulatory requirements (such as additional site characterization requirements). This selective use of strict liability is designed to provide an added incentive for site owners to select low-risk sequestration sites, particularly during the early phases of CCS deployment. As it stands, the EPA's Underground Injection Control (UIC) program is legally limited to setting minimum standards, which will not provide an incentive, particularly in the near term, for site operators to select the highest-quality sites. $\stackrel{286}{ }$

Consistent with the preceding discussion, we believe that uncertainties about the technical, economic, and political viability of CCS are far more significant than the speculative concerns about long-term liability and alleged large-scale risks associated with $\mathrm{CO}_{2}$ sequestration. However, the only way to begin the process of resolving these uncertainties about CCS viability is to construct full-scale CCS facilities, including sequestration sites. These efforts are being impeded, in part, by concerns about legal liability and risks to the environment and human health. Programs designed to promote deployment of CCS are unlikely to be successful without effective regulatory and liability policies, and ideally should be coordinated with them. The integration of regulatory and deployment policies is discussed in the final subsection below.

\section{A. The Current Legal Environment: Federal Versus State Regulation}

None of the existing federal laws, on its own, provides a comprehensive regulatory framework for carbon sequestration. The EPA currently regulates sequestration of $\mathrm{CO}_{2}$ through its UIC program under the SDWA. ${ }^{287}$ The UIC program was designed to regulate traditional threats to ground and surface water from toxic $\mathbf{* 5 5}$ contaminants, $\stackrel{288}{\text { but }}$ the EPA's authority to regulate

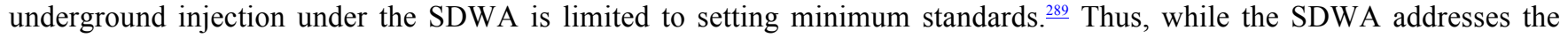
primary sources of risk (impacts on groundwater from $\mathrm{CO}_{2}$ or brine), to the extent that high-quality sites are more costly to purchase or operate (for example, because of deeper reservoirs), the law does not provide any incentives for companies to go beyond the EPA's minimum standards.

The limitations of other statutes are even greater. If $\mathrm{CO}_{2}$ were categorized as a "hazardous waste," its disposal could be controlled under the Resource Conservation and Recovery Act (RCRA), ${ }^{290}$ which imposes enhanced liability for environmental releases and a panoply of stringent regulations covering the "handling, storage, and disposal" of hazardous 
wastes. ${ }^{291}$ However, RCRA is directed almost exclusively at surface disposal of wastes. ${ }^{292}$ Similarly, sequestration sites will be regulated under the Clean Air Act, but such regulations would apply only to releases of $\mathrm{CO}_{2}$ directly into the atmosphere. $\frac{293}{}$ Finally, Superfund could be amended to cover releases of $\mathrm{CO}_{2}$ or brine into the environment, ${ }^{294}$ but it imposes an elaborate procedural architecture that is unlikely to be needed for sequestration sites ${ }^{295}$ and, of equal importance, would incite strong industry opposition given private sector aversion to Superfund.

Several states have passed, or are working to pass, sequestration-specific legislation, including limits on tort liability, rules for determining pore-space ownership, and laws covering the siting and operation of carbon sequestration sites. .96 These trends raise the $* \mathbf{5 6}$ prospect that the regulatory standards and potential tort liability applicable to geologic sequestration of $\mathrm{CO}_{2}$ will become an interstate patchwork that could undermine effective deployment of CCS. Industry representatives and commentators have already raised concerns that differences in legal regimes--rather than technical merits--may become a significant determinant of where companies choose to locate $\mathrm{CO}_{2}$ sequestration sites. ${ }^{297}$ One could also question whether state agencies and courts, particularly in states lacking experience with these types of activities (for example, with $\mathrm{CO}_{2}$-based enhanced oil recovery), will have the resources or expertise needed to oversee the operation of sequestration sites.

Reasonable arguments can be made both for and against uniform federal legislation that would preempt state laws. ${ }^{298}$ Regulation of impacts on drinking water under the SDWA, existing federal regulation of waste disposal and environmental releases of hazardous substances, and federal efforts to regulate $\mathrm{CO}_{2}$ emissions each provide solid precedent for federal-level legislation. Yet states retain regulatory authority over oil and gas development, which shares many regulatory issues with geologic sequestration of $\mathrm{CO}_{2}$ and is directly implicated when $\mathrm{CO}_{2}$ is used to enhance oil recovery. Further, carbon sequestration is likely to occur in only a small number of states (including Illinois, Ohio, and Texas) over the next few decades, ${ }^{299}$ which ought to diminish immediate concerns about the emergence of inconsistent and competing state-level legal regimes.

On balance we believe that the current regime of minimum performance-based standards under the SDWA, which place a floor on potential "races to the bottom" between states in setting *57 regulatory standards for sequestration sites, ought to be retained. The anti-regulatory bias of several of the states promoting CCS (Mississippi, Texas, and Wyoming, among others) suggests that such downward pressures are not merely speculative. These considerations are reinforced by the regional scale at which oversight of deep saline reservoirs should occur and by the fact that many reservoirs cross state lines, $\frac{301}{b}$ both of which raise the potential for interstate conflict. The critical importance of site selection to mitigating potential risks underscores the need for establishing a consistent set of minimum standards across the country to ensure that sites are selected for their merits rather than the regulatory environment.

Additionally, we see little downside to regulatory uniformity in the form of minimum performance standards given the limited range of risks involved. Notwithstanding the variability of site conditions, the basic attributes of the risks (threats to groundwater quality) are unlikely to vary markedly between well-selected sites. ${ }^{302}$ Similarly, the economies of scale that can be gained by centralizing regulation in the federal government, the perceived novelty of sequestering $\mathrm{CO}_{2}$ deep underground, and the global nature of climate change all favor a federal regulatory scheme. ${ }^{303}$ While we do not view the case for preemptive minimum federal standards as beyond dispute, numerous factors weigh in favor of it and few, if any, strongly against.

Minimum federal standards will not, however, ensure that the best sites are selected; instead, they will only exclude higherrisk sites from being developed. Yet, the surplus of available sites, persistent technical uncertainties, and political volatility surrounding geologic sequestration of $\mathrm{CO}_{2}$ all suggest that incentives for developing the lowest-risk sites during the early phases of CCS deployment ought to be a priority. The surplus of potential sites implies that there will be ample opportunity for early entrants to select low-risk sites. Similarly, although the absolute risks are projected to be low, the technical uncertainties leave open the potential for unanticipated releases to occur in an unforgiving political environment that is hypersensitive to any incidents involving environmental releases, regardless of their *58 impacts. Minimum federal standards, unless uncharacteristically risk averse, will not foreclose environmental releases that could trigger a major public backlash against CCS.

Tiered tort liability has the capacity to augment federal standards, particularly during the early stages of CCS deployment, by providing an added incentive for operators to select high-quality sites. While a tiered framework could be implemented 
through a regulatory regime, this approach would entail broader federal preemption of state regulations and, as discussed further in the next subsection, would be subject to the limitations--particularly information asymmetries--of a pure regulatory approach. It would also require legislative action extending the existing regulatory system under the SDWA, which, in the current political environment in Washington, D.C., is likely to provoke strong opposition in Congress. $\frac{304}{5}$

Our hybrid regime is less intrusive, although it would also require new legislation to establish a program for ranking sequestration sites, as well as rules governing liability for environmental releases from them. This hybrid approach has three primary virtues over a pure regulatory regime: First, the ranking system is a form of information-based regulation that is backed up by the incentives provided by common law liability, and as such avoids the trappings of "command and control" regulation that is likely to inspire the strongest opposition from regulatory critics. Second, our approach minimizes federal preemption of state programs; federal rules would merely dictate which sites could be subject to strict liability. $\frac{305}{5}$ Third, the imposition of enhanced liability on lower-ranked sequestration sites is supported by principles of economic efficiency and mitigated by the modest magnitude of the risks and liabilities at stake.

*59 The status of CCS as a new technology subject to a variety of informational constraints is another critical factor that places significant limits on ex ante regulation. In particular, the near-term releases projected by scientists to be the most significant--those from faults or abandoned wells--will be extremely difficult for a general regulatory regime to mitigate. $\frac{306}{}$ Accordingly, ex post liability is both better suited to addressing them and has the political virtues identified above.

These informational deficits, as we expect, are likely to diminish as deployment of CCS progresses. The experience and knowledge gained may allow the EPA's formal regulatory program to become more discriminating and to gain the capacity to mitigate these types of near-term risks, which in turn could allow the EPA to develop a more refined approach to regulating sequestration sites. If this occurs, a pure regulatory approach may be preferable, particularly as it may allow for a more fine-grained, multi-level categorization of sites. In the interim, the rough two-level system of tort liability that we are proposing would partially fill this temporary gap by exploiting the complementary strengths of an independent governmentbased system for ranking sites and the incentives provided by a decentralized liability-based system.

This hybrid framework would not be a cure-all, but that is neither achievable nor our objective. Throughout this article we wanted to examine the limits of tort liability in promoting safe deployment of CCS and how, given these constraints, tort liability could best be utilized towards this end. We have found that, for a variety of reasons, tort liability will be limited to playing only a supplementary role to traditional performance-based regulations. In this light, we have outlined how liability could be effectively leveraged in this secondary role; namely, to provide additional incentives for selection of low-risk sequestration sites.

\section{B. Creating Complementary Regulatory and Liability Regimes}

Similar to other commentators, we believe that regulation of sequestration sites should be structured around the different stages of site operations (active operation and injection of $\mathrm{CO}_{2}$, site closure, a 10 to 30 year period of post-closure monitoring and oversight, and finally long-term stewardship). .07 We also agree that when a site *60 transitions to long-term stewardship, it should be transferred to a government entity that will have sole responsibility for the sequestration site, including all liabilities.

However, our approach differs from other proposals in two primary respects: First, it emphasizes measures to promote selection of the safest sequestration sites and, in doing so, places less reliance on site monitoring and close oversight by federal regulators. Second, our framework integrates a formal regulatory regime and common law liability through a comprehensive system of mapping and ranking potential sequestration sites. This ranking would be conducted by a federal agency (most likely the U.S. Geological Survey) and used to determine whether a site will be subject to strict liability. The Department of Energy has already compiled a national database of prospective reservoirs for sequestration of $\mathrm{CO}_{2}$, which would support such a national assessment. $\frac{308}{}$

We believe that a rough ranking of sequestration sites would be neither technically demanding nor cost-prohibitive. $\frac{309}{}$ Well- 
established methods are available to analyze key factors, such as the depth of a proposed reservoir, density and depth of existing wells in the area, quality of the primary rock seal above a reservoir, vertical distance to the deepest freshwater aquifer, presence of potentially transmissive faults, and location of other risk receptors (for example, valuable overlying natural gas reservoirs)..$\frac{310}{} \mathrm{We}$ believe that the limited risk assessments needed to support such a ranking would, on a per-site basis, amount to a small fraction of the cost of a full site characterization. $\frac{311}{}$ Equally important, the ranking would be based on data that are quite accurate and straightforward to interpret. $\frac{312}{.2}$

*61 This informational approach draws on a hierarchical permitting system recently proposed by Jean-Philippe Nicot and Ian Duncan. .13 Under their scheme, a government agency would map, characterize, and rank deep brine reservoirs that are candidates for geologic sequestration of $\mathrm{CO}_{2} \cdot \frac{3.14}{}$ Rather than linking this assessment to liability, Nicot and Duncan adopt a pure regulatory approach that tiers permitting requirements (such as the extent of testing and information requirements) to the rank of each site, and they further suggest that regional-level permits could be developed under which site-specific permits be fast-tracked. $\frac{315}{5}$ Consistent with our approach, their framework emphasizes passive geological safety characteristics (for example, reservoir depth and impermeable cap rock layers) and is intended to complement the EPA's minimum performancebased standards. $\frac{316}{}$

The hybrid regulatory-liability framework that we propose could be used in conjunction with the Nicot-Duncan scheme, but the relative strengths of the two approaches will depend on specific attributes of the risks involved. As we have seen, two factors are critical to assessing the relative virtues of regulation versus liability: the latency of environmental harms and the information asymmetries between the private sector and the government. $\frac{317}{17}$ The greater the latency of leakage from carbon sequestration sites, the stronger the case for a pure regulatory regime and the less effective traditional common law liability. In opposition to this factor, the greater the information asymmetries between the private sector and the government, the more a liability regime is favored.

While significant uncertainties remain, scientific modeling has shown that the latency for leakage of $\mathrm{CO}_{2}$ is likely to last for many decades after injection, whereas releases of brine could arise within a decade. $\frac{318}{}$ If these projections prove accurate, the effectiveness of common law liability is likely to turn on the near-term risks *62 associated with brine releases. In general, lower-ranked sites, such as those in areas with many abandoned wells or with less reliable cap rock, will be more likely to leak early than highly ranked sites. Therefore, these characteristics would enhance the relative deterrence value of a liability regime for lower-quality sites.

Information asymmetries will nevertheless persist with a federal site-ranking program, as it would be limited to basic site characterization data. More detailed and new site information will become available only during the active $\mathrm{CO}_{2}$ injection phase of a sequestration site..$\frac{319}{}$ Moreover, while government regulations will require site operators to disclose at least some of this information, the EPA's capacity to monitor operations and emerging reservoir data will be limited by resources and time. $\frac{320}{1}$ As a consequence, information asymmetries could very well increase as operations at sequestration sites evolve and site operators gain direct experience.

The countervailing effects of latency and information asymmetries suggest three possible legal frameworks for the period spanning site selection, operation, and active post-closure. To the extent that latency is dominant, and thus liability largely ineffective, the Nicot-Duncan supplementary regulatory regime would be favored. Under this scheme, sites with lower scores could be subject to more stringent regulatory review and higher permitting fees (better sites could also be fast-tracked), $\mathrm{CO}_{2}$ mitigation credits could be discounted (if a U.S. market were established), or there could be some combination of both mechanisms. ${ }^{321}$ On the other end of the spectrum, if information asymmetries were dominant and latency minimal, a pure liability regime that incorporates a system of strict liability for all sites would be favored, as private knowledge would dominate.

We have shown that the risks of releases from sequestration sites will involve a mix of near-term risks from faults or abandoned wells, which initial site characterization is unlikely to identify, and risks subject to substantial periods of latency. ${ }^{.32}$ This mix of short- and longer-term risks combined with significant information gaps and asymmetries supports a hybrid regulatory-liability regime. While the *63 information gaps present when sites are permitted would undermine the efficiency of a tiered regulatory-only regime, they would not impede the effectiveness of an ex post liability regime. 
Similarly, while the latency of risks would erode the incentives provided by common law liability, minimum performancebased standards would place a lower limit on the effective magnitude of all risks, latent or otherwise, posed by sequestration sites. The regulatory and liability regimes thus complement each other by leveraging private knowledge to address risks that are inchoate when a site is permitted and by exploiting the robust public knowledge that is available upfront to establish minimum safety standards.

This hybrid framework is consistent with principles of economic efficiency and a precautionary approach to environmental protection. By using strict liability to promote selection of higher quality sequestration sites but making selection contingent on well-established criteria for site quality, the hybrid approach has the potential to mitigate industry opposition without sacrificing safety or efficiency. This approach is viable in significant part because a surplus of high-quality sites will exist for the next several decades, and it will be most effective during the early stages of CCS deployment when knowledge and experience are still being gained about the risks and reliability of sequestration sites. As the quality of information increases and the surplus of sites falls, we expect that the balance between regulation and liability will shift. Over time, more refined regulations will be possible, and the role of liability in providing meaningful incentives to select superior sites will diminish.

\section{Early-Stage Carbon Sequestration Projects}

The urgency surrounding mitigation of $\mathrm{CO}_{2}$ emissions places a premium on facilitating rapid development of CCS. Yet, the large technical hurdles, uncertainties about the integrity of sequestration sites, and the extremely large upfront capital demands of CCS projects collectively present major barriers to its deployment. Broad consensus exists that large-scale pilot projects will be essential to overcoming these barriers, particularly as many of them cannot be assessed reliably without fullscale plants and sequestration sites. $\frac{323}{} * 64$ Successful government involvement will almost certainly require some form of shared public-private projects, such as those incorporated into the failed Waxman-Markey climate change legislation that was passed by the U.S. House of Representatives in July 2009 but was never taken up by the Senate. $\frac{324}{}$

Industry concerns about liability have prompted a number of commentators to suggest that limiting liability (for example, capping damages under strict liability, similar to the Oil Pollution Act ${ }^{325}$ ) for leakage from early-stage carbon sequestration sites could promote early entrants into the CCS industry. ${ }^{326}$ We believe that this is unnecessary because the projected magnitude of the potential damages is modest, implying that a cap would be unnecessary. Put differently, it would be extremely unlikely that the damages associated with releases from a sequestration site would ever exceed the strict liability cap. However, industry may still desire such a cap given the novelty of geologic sequestration. If the cap is set sufficiently high (that is, above reasonably projected impacts), it need not be inconsistent with our hybrid approach. We expect politically viable caps would not be a problem given the modest levels of the projected impacts, and we thus believe that there need not be a conflict between our tiered approach and those of other commentators. That said, in practice we anticipate that such liability caps will have little more than symbolic value.

The need for additional incentives to encourage early entrants is significant, but the primary barriers to CCS deployment are the large upfront economic costs and remaining technological uncertainties, particularly with respect to capturing $\mathrm{CO}_{2}$. Addressing them will require creative use of public-private partnerships, tax incentives, and direct subsidies, each of which has been incorporated into prior climate change bills in Congress, most notably the Waxman-Markey bill. $\frac{327}{}$ While each of these alternatives has significant fiscal implications at a time of economic austerity in the United States, the use of liability caps cannot surmount these barriers because they are not designed to mitigate or overcome them. Tort liability is directed at negative externalities, whereas the primary barriers to deployment ${ }^{*} \mathbf{6 5}$ of CCS involve unrelated technological uncertainties that will not be affected by a liability cap.

One final point is worth highlighting: the complementary roles that regulation and tort liability can play are of particular importance to geologic carbon sequestration. The novelty of carbon sequestration is already raising public fears. $\frac{328}{}$ Overcoming these fears will require concerted efforts by the industry, government, and non-governmental organizations to promote operational transparency and public understanding of carbon sequestration.

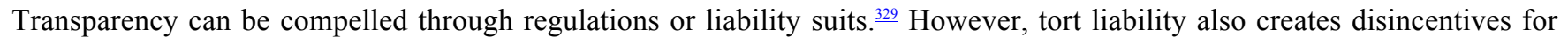


companies to collect information that could be used against them in a lawsuit. $\frac{330}{5}$ Ensuring that regulations and tort liability are harmonized to promote transparency will be especially important because the industry will possess detailed site information that, unless obtained through regulatory channels, will not be available to state and federal agencies. 331 Reporting requirements that apply to all $\mathrm{CO}_{2}$ emissions ought to ensure that most of the relevant information is public, but insofar as they do not, it will be imperative that sequestration-site-specific reporting requirements are in place and rigorously enforced to ensure that regulations keep up with evolving sequestration technologies and knowledge. $\frac{332}{2}$

\section{Conclusion}

This article challenges several misconceptions about the risks associated with geologic sequestration of $\mathrm{CO}_{2}$ and the significance of open-ended legal liability. We have shown that the current debate is overly focused on the risks associated with $\mathrm{CO}_{2}$ leakage and $* \mathbf{6 6}$ insufficiently attentive to the primary source of risk--releases of brine into drinking water aquifers. This oversight has important legal implications because the nature and timing of the two types of risks are quite different. As a general rule, releases of brine are much more likely and are projected to occur much earlier in the lifecycle of a sequestration site than releases of $\mathrm{CO}_{2}$.

Understanding the nature of these risks, particularly their modest impacts and relative simplicity, ought to diffuse the controversy over legal liability for CCS. As we have demonstrated, loss of incentives provided by long-term liability is ultimately of negligible importance. Nevertheless, near-term liability can play a meaningful role, albeit a limited one, if it is directed primarily at risks associated with releases of brine.

Our analysis also reveals that principles of economic efficiency support imposing either strict liability or negligence, although a stronger case exists for strict liability. We advocate a two-tiered system of liability that is based on two distinct classes of decisions--site selection and operational judgments--that operates in parallel with minimum federal performance standards. This tiered hybrid approach leverages public and private information to enhance efficiency. However, we ultimately advocate this approach to mitigate problems with low political viability that would be associated with an effort to impose strict liability on owners or operators of sequestration sites.

\section{Footnotes}

d1 David E. Adelman holds the Harry Reasoner Regents Chair in Law at the University of Texas School of Law; Ian J. Duncan is a Research Scientist in the Bureau of Economic Geology at the University of Texas at Austin.

$1 \quad$ See, e.g., Chad Livengood, Missouri Utilities Seek Cap on Liability from Carbon Sequestration, Citizens Against CO2 Sequestration (May 25, 2009, 1:52 PM), http://citizensagainstco2sequestration.blogspot/2009/05/missouri-utilities-seek-capon.html; Greenpeace Int'1, False Hope: Why Carbon Capture and Storage Won't Save the Climate 30-31(2008) [hereinafter Greenpeace], available at http://www.greenpeace.org/usa/Global/usa/report/2008/5/false-hope-why-carbon-capture.pdf.

2 The economics alone are sobering. According to the International Energy Agency (IEA), the annual costs of cutting global $\mathrm{CO}_{2}$ emissions in half by 2050 would increase by $71 \%$ (\$1.28 trillion per year) without CCS. Int'l Energy Agency, Energy Technology Analysis: CO2 Capture and Storage: A Key Carbon Abatement Option 16 (2008) [hereinafter IEA], available at http:// www.iea.org/textbase/nppdf/free/2008/CCS_2008.pdf. The IEA concludes, "CCS is therefore essential to the achievement of deep emission cuts." Id. at 15 .

$3 \quad$ Steven Chu, Carbon Capture and Sequestration, 325 Science 1599, 1599 (2009).

$4 \quad$ See, e.g., Vello A. Kuuskraa, A Program to Accelerate Deployment of CO2 Capture and Storage (CCS): Rationales, Objectives, and Costs 7 (2007), available at http://www.pewclimate.org/docUploads/CCS-Deployment.pdf (arguing that "if the United States 
is to address global climate change in a meaningful way... [CCS] becomes a primary option”); David G. Hawkins et al., Carbon Capture and Storage: What To Do, 295 Sci. Am. 68, 75 (2006) (arguing that "[a]n integrated low-carbon energy strategy that incorporates [CCS] can reconcile substantial use of coal... with the imperative to prevent [climate change]"); Scott Anderson, Sequestering Carbon Deep Within the Earth, Climate 411 Blog (Mar. 3, 2008), http://blogs.edf.org/climate411/2008/03/03/geosequestration/ (asserting that "CCS is a critical transition technology").

$5 \quad$ Commission Proposal for a Directive of the European Parliament and of the Council on the Geologic Storage of Carbon Dioxide and Amending Council Directives, at 1, COM (2008) 18 final (Jan. 23, 2008), available at http://eurlex.europa.eu/LexUriServ/LexUriServ.do?uri=COM:2008:0018:FIN:EN:PDF. The European Union's Directive on Geologic Storage of Carbon Dioxide was adopted on April 23, 2009. Council Directive 2009/31, 2009 O.J. (L 140/114) (EN), available at http://eur-lex.europa.eu/LexUriServ/LexUriServ.do? uri=OJ:L:2009:140:0114:0135:EN:PDF.

See, e.g., Chiara Trabucchi et al., A Multi-Disciplinary Framework to Monetize Financial Consequences Arising from CCS Projects and Motivate Effective Financial Responsibility, 4 Int'1 J. Greenhouse Gas Control 388, 388-89 (2010); Greenpeace, supra note 1 , at 30-31.

See IEA, supra note 2, at 106.

This assumes that the $\mathrm{CO}_{2}$ is being compressed to a pressure of 10 megapascals (MPa), which is typical of pressures in $\mathrm{CO}_{2}$ pipelines, and has a density of about 800 kilograms per cubic meter; the capacity of a supertanker, two million barrels of oil, is based on the largest class of such ships.

IEA, supra note 2, at 106 .

See, e.g., Greenpeace, supra note 1, at 30.

See Filip Johnsson et al., Stakeholder Attitudes on Carbon Capture and Storage--An International Comparison, 4 Int'1 J. Greenhouse Gas Control 410, 417 (2010); Jennie Stephens et al., Learning About Carbon Capture and Storage: Changing Stakeholder Perceptions with Expert Information, 1 Energy Procedia 4655, 4656 (2009); U.S. Energy Info. Admin., Annual Energy Outlook 201142 (2011), available at http://www.eia.gov/forecasts/aeo/pdf/0383\%282011\% 29.pdf.

See generally Greenpeace, supra note 1 , at 5; IEA, supra note 2, at 15-16.

See infra Part I.A.

See infra Part II.

James A. Holtkamp, Models Studied for Long-Term Liability Risks in CCS, 24 Nat. Gas \& Electricity 12, 12 (2008) (arguing that liability for long-term risks "is a major disincentive... to implement[ing] CCS on a commercial scale"); CCS Alliance, Study of Legal Issues Relating to Risk and Liability in Connection with Carbon Capture and Storage 58 (2008), available at http:// www.huntonfiles.com/files/webupload/CCS_liability_report_7.23.08.pdf (concluding that "uncertainty over long-term liability issues... has deterred project developers, financiers, and insurers").

See, e.g., David Hawkins et al., Twelve Years After Sleipner: Moving CCS From Hype to Pipe, 1 Energy Procedia 4403, 4407 (2009); Elizabeth J. Wilson et al., Assessing a Liability Regime for Carbon Capture and Storage, 1 Energy Procedia 4575, 4575 
(2009) [hereinafter Wilson et al., Assessing]; IEA Greenhouse R\&D Programme, Expert Workshop on Financing Carbon Capture and Storage: Barriers and Solutions 25-26 (2007).

17 See, e.g., Mark A. de Figueiredo et al., Framing the Long-Term in Situ Liability Issue for Geologic Carbon Storage in the United States, 10 Mitigation \& Adaptation Strategies for Global Change 647, 650, 652-53 (2005); Charles H. Haake \& Karyn B. Marsh, The Trouble with Angels: Carbon Capture and Storage Hurdles and Solutions, Bureau of Nat'l Affairs World Climate Change Rep., May 8, 2009, at 5-6; Alexandra B. Klass \& Elizabeth J. Wilson, Climate Change and Carbon Sequestration: Assessing a Liability Regime for Long-Term Storage of Carbon Dioxide, 58 Emory L.J. 103, 128-32, 164-71 (2008).

See infra Part III.B.2.

See infra Part I.A.

See Johannes E. Kalunka et al., Effects of CO2 Storage in Saline Aquifers on Ground Water Supplies 7-9 (2010) (prepared for Society of Petroleum Engineers International Conference on $\mathrm{CO}_{2}$ Capture, Storage, and Utilization, New Orleans, Louisiana, November 10-11, 2010), available at http:// www.onepetro.org/mslib/servlet/onepetropreview?id=SPE-139665-MS\&soc=SPE (presenting simulations suggesting that large-scale sequestration of $\mathrm{CO}_{2}$ will have minimal impacts on overlying aquifers); see also Martin Iding \& Philip Ringrose, Evaluating the Impact of Fractures on the Performance of the In Salah CO2 Storage Site, 4 Int'1 J. Greenhouse Gas Control 242, 243 (2010); Youngsoo Lee et al., Analysis of the Leakage Possibility of Injected CO2 in a Saline Aquifer, 24 Energy Fuels 3292, 3297-98 (2010).

Martha L. Judy \& Katherine N. Probst, Superfund at 30, 11 Vt. J. Envtl. L. 191, 192-93 (describing "Love Canal" and "Valley of the Drums," two prominent release sites that spurred adoption of the Comprehensive Environmental Response, Compensation,

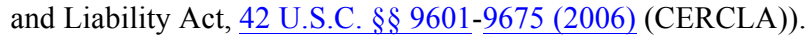

Quanlin Zhou et al., Modeling Basin- and Plume-Scale Processes of CO2 Storage for Full-Scale Deployment, 48 Ground Water 494, 495 (2010) ("[M]uch less effort has been devoted to studying transport phenomena of resident fluids (i.e., brine in saline aquifers) at a scale of sedimentary basins."): see also Jens T. Birkholzer \& Quanlin Zhou, Basin-Scale Hydrogeologic Impacts of CO2 Storage: Capacity and Regulatory Implications, 3 Int'1 J. Greenhouse Gas Control 745, 746 (2009) (one of the recent studies evaluating the effects of CCS on brine displacement); Jean-Philippe Nicot, Evaluation of Large-Scale CO2 Storage on Fresh-Water Sections of Aquifers: An Example from the Texas Gulf Coast Basin, 2 Int'1 J. Greenhouse Gas Control 582, 582-83 (2008) [hereinafter Nicot, Fresh-Water] (same).

\section{See infra Part I.B.}

Kalunka et al., supra note 20, at 5, 8-9; see also infra Part I.B.

See infra Part I.B.

See, e.g., World Res. Inst., CCS Guidelines: Guidelines for Carbon Dioxide Capture, Transport, and Storage 55 (2008); Envtl. Prot. Agency, EPA430-R-08-009, Technical Support Document: Vulnerability Evaluation Framework for Geologic Sequestration of Carbon Dioxide 44 (2008) [hereinafter EPA], available at http://www.epa.gov/climatechange/emissions/downloads/VEFTechnical_Document_072408.pdf (arguing that post-injection wells will still pose small leakage risks, but not to the extent that could affect human health); Chiara Trabucchi \& Lindene Patton, Storing Carbon: Options for Liability Risk Management, Financial Responsibility, Bureau of Nat'l Affairs, Daily Env't Rep., Sept. 3, 2008, at 11-13, available at http://www.indecon.com/iec_web/expertise/BNACCSFR_9032008.pdf. 
See Frank B. Walton et al., Geological Storage of CO2: A Statistical Approach to Assessing Performance and Risk, in Proceedings of 7th International Conference on Greenhouse Gas Control Technologies (E.S. Rubin et al. eds., 2004), available at http://www.granite.mb.ca/ sheppard/GHGT7.pdf (asserting the possibility of brine intrusion hundreds of years after initial injection); Trabucchi \& Patton, supra note 26, at 13; infra Part I.B.

See Robert L. Rabin, Environmental Liability and the Tort System, 24 Hous. L. Rev. 27, 43 (1987) (listing "long gestation" as a factor that undercuts the deterrent effect of tort liability).

See infra Part II.A.

Supercritical $\mathrm{CO}_{2}$ has the properties of low viscosity and density relative to standard liquids and, most importantly here, water. U.S. Dep't of Energy, 2010 Carbon Sequestration Atlas of the United States and Canada 26 (3d ed. 2010) [hereinafter DOE Atlas], available at http:// www.netl.doe.gov/technologies/carbon_seq/refshelf/atlasIII/2010atlasIII.pdf.

For the practical purpose of limiting its volume, sequestration of $\mathrm{CO}_{2}$ is limited to depths below 800 to 1500 meters (2600 to 4900 feet), depending on the geologic conditions. Chin-Fu Tsang et al., Scientific Considerations Related to Regulation Development for CO2 Sequestration in Brine Formations, 42 Envtl. Geology 275, 277 (2002).

Sally M. Benson \& Terry Surles, Carbon Dioxide Capture and Storage: An Overview with Emphasis on Capture and Storage in Deep Geological Formations, 94 Proc. IEEE 1795, 1802 (2006) (noting that approximately 75\% of the costs of CCS are attributable to the capture and compression of $\mathrm{CO}_{2}$ ). Current best estimates indicate that the total costs of CCS will be $\$ 20$ to $\$ 70$ per metric ton of $\mathrm{CO}_{2}$, which translates to increases of $\$ 0.01$ to $\$ 0.05$ per kilowatt-hour $(\mathrm{kWh})$ for electric power from coal-fired power plants. For a typical plant, the projected cost increase is $\$ 0.025$ per $\mathrm{kWh}$, which is approximately $50 \%$ above current baseload costs. Id.

Curtis M. Oldenburg et al., Certification Framework Based on Effective Trapping for Geological Carbon Sequestration, 3 Int'l J. Greenhouse Gas Control 444, 445 (2009) [hereinafter Oldenburg et al., Certification Framework]. For example, the quantity of contaminated water produced from oil and gas in Texas was 850 metric tons in 2002, which is more than double the amount of $\mathrm{CO}_{2}$ (equivalent to about 370 metric tons of water) emitted by Texas power plants. Nicot, Fresh-Water, supra note 22, at 583. Some municipalities also dispose of large volumes of wastewater via deep underground injection. Id.

Intergovernmental Panel on Climate Change, IPCC Special Report on Carbon Capture and Storage 211 (Bert Metz et al. eds., 2005) [hereinafter IPCC], available at http://www.ipcc.ch/pdf/special-reports/srces/srces_ wholereport.pdf (concluding that the release of $\mathrm{CO}_{2}$ from Lake Nyos is "not representative of the seepage through wells or fractures that may occur from underground geological storage sites").

Franklin M. Orr, Jr., Onshore Geologic Storage of CO2, 325 Science 1656, 1656-57 (2009) (finding that "[e]stimates of worldwide potential storage capacity range from 1700 to almost 11,000 gigatons of $\mathrm{CO}_{2}$ "). Please note that this discussion does not include alternative modes of geologic sequestration, such as storage of $\mathrm{CO}_{2}$ in depleted oil fields or in un-minable coal beds, which would augment the capacity for geologic sequestration of $\mathrm{CO}_{2}$ described here.

Daniel P. Schrag, Making Carbon Capture and Storage Work, in Acting in Time on Energy Policy 46 (Kelly Sims Gallagher ed., 2009).

Birkholzer \& Zhou, supra note 22, at 745. 
$\underline{38}$

Benson \& Surles, supra note 32, at 1796; see also IPCC, supra note 34, at 34 (estimating global capacity of brine reservoirs is at least $1000 \mathrm{Gt}$ of $\mathrm{CO}_{2}$ ); IEA, supra note 2, at 106 (estimating global capacity of brine reservoirs to be 2000 to $20,000 \mathrm{Gt}^{\circ} \mathrm{CO}_{2}$ ).

U.S. Energy Info. Admin., Int'l Energy Outlook 7 (2010).

This second calculation assumes that the electric power sector accounts for forty percent of global $\mathrm{CO}_{2}$ emissions. See Int'l Energy Agency, CO2 Emissions from Fuel Combustion: Highlights 9 (2010), available at http:// www.iea.org/co2highlights/co2highlights.pdf.

41 IPCC, supra note 34, at 33, 43-46.

2 Id. at $31-32$.

Benson \& Surles, supra note 32 , at 1799-1800.

4 Sally M. Benson \& David Cole, CO2 Sequestration in Deep Sedimentary Formations, 4 Elements 325, 326-28 (2008).

Benson \& Surles, supra note 32, at 1800; Tsang et al., supra note 31, at 278-79.

IPCC, supra note 34, at 31 .

Id. at 32 (describing how multiple processes--including retention by cap rock, dissolution of $\mathrm{CO}_{2}$ in native brines, capillary trapping, and mineral trapping--will independently operate to retain $\mathrm{CO}_{2}$ in deep brine reservoirs,); see also Tsang et al., supra note 31, at 279; Benson \& Surles, supra note 32, at 1800.

Benson \& Surles, supra note 32, at 1800.

Id.; see also Tsang et al., supra note 31, at 279.

Ian J. Duncan et al., Risk Assessment for Future CO2 Sequestration Projects Based on CO2 Enhanced Oil Recovery in the U.S., 1 Energy Procedia 2037, 2037 (2009).

1 IPCC, supra note 34, at 32-33.

52 Id. at 34; Tsang et al., supra note 31, at 279-80 (“[M] possible faults and fractures is needed.").

3 IPCC, supra note 34, at 375 (describing the comparative advantages of $\mathrm{CO}_{2}$ sequestration in deep brine reservoirs over sequestration in the terrestrial biosphere); J.J. Hutchinson et al., Some Perspectives on Carbon Sequestration in Agriculture, 142 Agric. \& Forest Meteorology 288, 289-90 (2007); Klass \& Wilson, supra note 17, at 167 (observing that "CCS risks are generally understood and likely manageable"). 
See, e.g., S. Julio Friedmann, Geological Carbon Dioxide Sequestration, 3 Elements 179, 182-83 (2007); Michael Stenhouse et al., Assessing Environmental Impacts from Geological CO2 Storage, 1 Energy Procedia 1895, 1900 (2009). See generally IPCC, supra note 34, at 247-48 (discussing risks to groundwater from $\mathrm{CO}_{2}$ and brine leakage); Kate Robertson et al., International Carbon Capture and Storage Projects: Overcoming Legal Barriers 9 (2006), available at http://www.netl.doe.gov/energyanalyses/pubs/ccsregulatorypaperfinalreport.pdf (noting the importance and difficulty of designing wells to prevent seepage).

See, e.g., Christian D. Klose, Human-Triggered Earthquakes and Their Impacts on Human Security, in Achieving Environmental Security: Ecosystem Services and Human Welfare 14 (P.H. Liotta et al. eds., 2010); Joel Sminchak \& Neeraj Gupta, Issues Related to Seismic Activity Induced by the Injection of CO2 in Deep Saline Aquifers, 2 J. Energy \& Envtl. Res. 32, 39-40 (2002), available at http://www.netl.doe.gov/publications/journals/vol2_no1.pdf. catastrophic in nature, while others are recurring and of modest severity.").

See Duncan et al., supra note 50, at 2037-38; Kalunka et al., supra note 20, at 8-9; Trabucchi \& Patton, supra note 26, at 11 (concluding that water resources are at risk if either $\mathrm{CO}_{2}$ or brines escape the sequestration reservoir); J.A. Apps et al., Evaluation of Potential Changes in Groundwater Quality in Response to CO2 Leakage from Deep Geologic Storage, 82 Transp. Porous Media 215, 216 (2010) (explaining that dissolution of $\mathrm{CO}_{2}$ in aquifers can release toxic heavy metals).

See Trabucchi \& Patton, supra note 26, at 10-11; IPCC, supra note 34, at 34-35.

In a recent simulation study involving leakage from an abandoned well, scientists found that the likelihood of impacts on human health in buildings was negligible and that ecosystem impacts were either negligible or highly localized around the area of leakage. Oldenburg et al., Certification Framework, supra note 33, at 454-55. Plausible leakage rates were the equivalent of "driving a 20[mile-per-gallon] car approximately 5 miles per day.” Id. at 455.

See, e.g., Karsten Pruess, On CO2 Fluid Flow and Heat Transfer Behavior in the Subsurface, Following Leakage from a Geologic Storage Reservoir, 54 Envtl. Geology 1677, 1684 (2008) (concluding that "leakage of $\mathrm{CO}_{2}$ from a deep geologic reservoir as such does not appear capable of producing a concentrated high-energy discharge at the land surface"); Jean-Philippe Nicot \& Ian J. Duncan, Science-Based Permitting of Geological Sequestration of CO2 in Brine Reservoirs in the U.S., 11 Envtl. Sci. \& Pol'y 14, 21 (2008); Elizabeth J. Wilson et al., World Res. Inst., WRI Issue Brief, Carbon Capture and Sequestration no. 3: Liability and Financial Responsibility Frameworks for Carbon Capture and Sequestration 3 (2007) [hereinafter Wilson et al., Liability], available at http://pdf.wri.org/liability-and-financial-responsibility.pdf (concluding that "properly planned and operated CCS projects are extremely unlikely to threaten human life"); IPCC, supra note 34 , at 34.

Mark A. de Figueiredo et al., Regulating Carbon Dioxide Capture and Storage 9 (MIT Ctr. for Energy and Envtl. Policy, Working Paper No. 3, 2007), available at http://web.mit.edu/ceepr/www/publications/workingpapers/2007-003.pdf (concluding that "[p]robably the most likely mechanism for loss of containment would be via abandoned wells."); IPCC, supra note 34 , at 372 ("The probabilities of physical leakage are estimated to be small and the risks are mainly associated with leakage from well casings of abandoned wells."); Yingqui Zhang et al., Probability Estimation of CO2 Leakage Through Faults at Geologic Carbon Sequestration Sites, 1 Energy Procedia 41, 41 (2009); Kalunka et al., supra note 20, at 8-9; EPA, supra note 26 , at 45. sequestration.mit.edu/pdf/GHGT8_Ide.pdf (concluding that $\mathrm{CO}_{2}$ leakage through wells remains a "substantial risk" in geologic sequestration projects); Barbara G. Kutchko et al., Degradation of Well Cement by CO2 Under Geologic Sequestration Conditions, 41 Envtl. Sci. \& Tech. 4787, 4791 (2007) ("Although it is clear that cement is degraded by exposure to $\mathrm{CO}_{2} \ldots$ the degradation processes involved are slow.”); Walter Crow et al., Wellbore Integrity Analysis of a Natural CO2 Producer, 1 Energy Procedia 
3561,3568 (concluding that "cement systems can be used effectively in creating suitable barrier systems for long-term $\mathrm{CO}_{2}$ storage operations, if good practices are employed during well construction").

IPCC, supra note 34, at 34; Kalunka et al., supra note 20, at 8-9. Limitations in the resolution of existing methods for mapping subsurface faults preclude identifying many small faults. Curtis M. Oldenburg et al., Risk Assessment Framework for Geologic Carbon Sequestration Sites 4 (2010), available at http://escholarship.org/uc/item/8297g3k2 [hereinafter Oldenburg et al., Risk Assessment]; Alv-Arne Grimstad et al., Modelling and Simulation of Mechanisms for Leakage of CO2 from Geologic Storage, 1 Energy Procedia 2511, 2512 (2009) (arguing that "[d]iffuse leakage through fractures or pore-space of the cap-rock... will be more difficult to detect and remedy. These mechanisms may therefore be the largest contributor to leakage of stored $\mathrm{CO}_{2}$," but also the slowest.); Jens T. Birkholzer et al., Large-Scale Impact of CO2 Storage in Deep Saline Aquifers: A Sensitivity Study on Pressure Response in Stratified Systems, 3 Int'1 J. Greenhouse Gas Control 181, 182 (2009).

IPCC, supra note 34, at 34; Curtis M. Oldenburg, Screening and Ranking Framework for Geologic CO2 Storage Site Selection on the Basis of Health, Safety, and Environmental Risk, 54 Envtl. Geology 1687, 1687 (2008) [hereinafter Oldenburg, Screening] (observing that, other than site operation decisions, "the best way to avoid unintended leakage and seepage is to choose a good site at the outset"); Vello A. Kuuskraa, Cost-Effective Remediation Strategies for Storing CO2 in Geologic Formations 1 (2009) (prepared for Society of Petroleum Engineers International Conference on $\mathrm{CO}_{2}$ Capture, Storage, and Utilization, San Diego, California, November 2-4, 2009), available at http:/www.onepetro.org/mslib/servlet/onepetropreview?id=SPE-126618MS\&soc=SPE; Trabucchi \& Patton, supra note 26, at 9 (observing that the magnitude of long-term risks "will depend on near-term decisions involving the siting and operation phases of the sequestration process").

See, e.g., Jean-Philippe Nicot et al., Investigation of Water Displacement Following Large CO2 Sequestration Operations, 1 Energy Procedia 4411, 4411 (2009) [hereinafter Nicot et al., Investigation]; Nicot, Fresh-Water, supra note 22, at 582-84; JeanPhilippe Nicot et al., Pressure Perturbations from Geologic Carbon Sequestration: Area-of-Review Boundaries and Borehole Leakage Driving Forces, 1 Energy Procedia 47, 54 (2009) [hereinafter Nicot et al., Pressure]; Birkholzer et al., supra note 63, at $182-83$.

See, e.g., Birkholzer et al., supra note 63, at 193; Nicot et al., Investigation, supra note 65, at 4413; Kalunka et al., supra note 20, at 5. The EPA recognized the importance of brine intrusion and the large geographical area of elevated reservoir pressures prior to the publication of its final rules under the Safe Drinking Water Act that will govern sequestration site selection, operation, and closure. See Federal Requirements Under the Underground Injection Control Program for Carbon Dioxide Geologic Sequestration Wells, 75 Fed. Reg. 77,230, 77,248-49 (Dec. 10, 2010) (to be codified at 40 C.F.R. pts. 124, 144, 145, 146, \& 147) (describing the EPA's decision to expand the definition of the "area of review" for regulatory purposes to include the "associated pressure front" and "displaced fluids"). The EPA defines the "pressure front" as "a zone where there is a pressure differential sufficient to cause the movement of injected fluids or formations fluids into a USDW [underground source of drinking water].” Id. at 77,292.

Stefan Bachu, CO2 Storage in Geological Media: Role, Means, Status and Barriers to Deployment, 34 Progress Energy \& Combustion Sci. 254, 265 (2008); Steven L. Bryant et al., Buoyancy-Dominated Multiphase Flow and Its Impacts on Geologic Sequestration of CO2, 13 Soc'y of Petroleum Engineers J. 447, 447 (2006), available at http://science.uwaterloo.ca/ mauriced/earth691-

duss/CO2_General\%20CO2\%C20Sequestration\%20materilas/CO2_BRYANT_BuoyancyFlow\%20and\%C20CO2\%C20Sequestrat ion\%2008_SPE-99938-PA-P.pdf. 
$\underline{71}$

Birkholzer et al., supra note 63 , at 182-83.

Kalunka et al., supra note 20, at 4-5, 7-9; Iding \& Ringrose, supra note 20, at 242-43; Nicot et al., Pressure, supra note 65, at 47-48.

Kalunka et al., supra note 20, at 9 (concluding that "[b]rine leakage and pressure changes, rather than $\mathrm{CO}_{2}$ migration, are the main problems associated with large-scale [carbon sequestration].... [u]nless an abandoned well is within or laterally very near the $\mathrm{CO}$ plume, $\mathrm{CO}_{2}$ leakage is minimal"); Nicot, Fresh-Water, supra note 22, at 589-90 (concluding that "[t]he pressure pulse travels much faster than the mass of the $\mathrm{CO}_{2}$ plume"); Nicot et al., Pressure, supra note 65, at 47 ("[T]he influence of the zone of elevated pressure during injection on potential conduits such as well boreholes and faults could extend many kilometers from the injection site--much farther than the $\mathrm{CO}_{2}$ plume itself."); Zhou et al., supra note 22, at 508 (finding that "the pressure-affected pore volume is orders of magnitude larger than the subsurface pore volume affected by free-phase $\mathrm{CO}_{2}$ ").

Nicot, Fresh-Water, supra note 22, at 589-90.

Kalunka et al., supra note 20, at 4-5; see also Seyyed M. Ghaderi et al., Feasibility of Injecting Large Volumes of CO2 into Aquifers, 1 Energy Procedia 3113, 3117-18 (modeling a $\mathrm{CO}_{2}$ plume radius of 4.6 kilometers and a pressure field of 65 kilometers after 50 years of injecting $\mathrm{CO}_{2}$ ); Lee et al., supra note 20, at 3296-97; Mark Person et al., Assessment of Basin-Scale Hydrologic Impacts of CO2 Sequestration, Illinois Basin, 4 Int'1 J. Greenhouse Gas Control 840, 851-52 (2010); M. Winkler et al., The Dynamic Aspect of Formation Storage Use for CO2 Sequestration 10 (2010) (prepared for Society of Petroleum Engineers International Conference on $\mathrm{CO}_{2}$ Capture, Storage, and Utilization, New Orleans, Louisiana, November 10-11, 2010), available at $\mathrm{http}: / / \mathrm{www}$.onepetro.org/mslib/servlet/onepetropreview?id=SPE-139730-MS\&soc=SPE.

Zhou et al., supra note 22, at 500 (describing the study, which involved twenty injection wells spaced, on average, about $30 \mathrm{~km}$ apart, with each well injecting $5 \mathrm{Mt}$ per year of $\mathrm{CO}_{2}$ over 50 years).

Id. at 504 .

Id. at 503-04.

Id. at 506 .

Id.

See id. at 507 fig. 8 .

Birkholzer \& Zhou, supra note 22, at 750.

Zhou et al., supra note 22, at 509 (finding that cumulative leakage accounted for just $9.5 \%$ of the displaced brine over the first 50 years of injection, with the remaining $90 \%$ offset by changes in pore-space volume caused by the elevated reservoir pressures).

Id. at 509-10 (finding that it was not until 200 years after injection that cumulative leakage accounted for $62 \%$ of brine displacement in the reservoir). 
$\underline{85}$

Id. at 511 .

Kalunka et al., supra note 20, at 8-9.

Birkholzer \& Zhou, supra note 22, at 746 (concluding that the impacts from brine flow may be "the limiting factor determining the $\mathrm{CO}_{2}$ sequestration capacity in large sedimentary basins").

Id. at 754 .

Id.

Id.

Indivisible causation involves circumstances in which the contributions of different defendants to an alleged harm cannot be separated from each other. 1 Dan B. Dobbs, The Law of Torts 422-23 (2001) [hereinafter Dobbs, Torts].

Oldenburg et al., Risk Assessment, supra note 63, at 10.

See, e.g., id.; O. Bouc et al., CO2 Geological Storage Safety Assessment: Methodological Developments 10-12 (2010) (prepared for 10th International Probabilistic Safety Assessment \& Management Conference, Seattle, Washington, June 7-11, 2010), available at http://hal-brgm.archives-ouvertes.fr/docs/00/50/25/92/PDF/PSAM10-BOUC_vfin.pdf; Lisa Bacanskas et al., Toward Practical Application of the Vulnerability Evaluation Framework for Geological Sequestration of Carbon Dioxide, 1 Energy Procedia 2565, 2571 (2009).

See, e.g., Lesley K. McAllister, The Enforcement Challenge of Cap-and-Trade Regulation, 40 Envtl. L. 1195, 1196-97 (2010); Edward Vine et al., International Greenhouse Gas Trading Programs: A Discussion of Measurement and Accounting Issues, 31 Energy Pol'y 211, 212-13 (2003); Michael W. Wara \& David G. Victor, A Realistic Policy on International Carbon Offsets 8 (Program on Energy \& Sustainable Dev., Working Paper, No. 74, 2008), available at http://iisdb.stanford.edu/pubs/22157/WP74_final_final.pdf (detailing the "flaws" in the UNFCCC's Clean Development Mechanism carbon offsets program).

See generally IPCC, supra note 34, at 47 ("Recognizing the potential impermanence of $\mathrm{CO}_{2}$ stored in the terrestrial biosphere, the UNFCCC accepted the idea that net emissions can be reduced through biological sinks, but has imposed complex rules for such accounting.").

7 Sally M. Benson et al., Monitoring Carbon Dioxide Sequestration in Deep Geologic Formations for Inventory Verification and Carbon Credits 3 (2006) (prepared for 2006 Society of Petroleum Engineers Annual Technical Conference and Exhibition, San Antonio, Texas, September 24-27, 2006), available $\quad$ at $\quad$ http:// www.energy.utah.gov/government/docs/forum/dec2006/spe102833.pdf.

IPCC, supra note 34 , at 46. 
Id. at 46-47. However, experience with regulation of traditional pollutants in the U.S. suggests that accounting for fugitive emissions is often subject to large uncertainties and difficult to verify. See, e.g., U.S. Envtl. Prot. Agency, Proper Monitoring Essential to Reducing 'Fugitive Emissions' Under Leak Detection and Repair Programs, Enforcement Alert, Oct. 1999, at 2-3.

See Alexandra B. Klass \& Elizabeth J. Wilson, Carbon Capture and Sequestration: Identifying and Managing Risks, 8 Issues in Legal Scholarship 1, 14 (2009).

IPCC, supra note 34, at 34; Bachu, supra note 69, at 266.

See IPCC, supra note 34, at 371 ("There is insufficient experience in monitoring CCS projects to allow conclusions to be drawn on physical leakage rates.").

See generally Lambert Schneider, Assessing the Additionality of CDM Projects: Practical Experiences and Lessons Learned, 9 Climate Pol'y 242, 250-51 (2009) (discussing “serious weaknesses" in the UNFCCC carbon offsets program's measure of project effectiveness); Wara \& Victor, supra note 95 , at 8.

See generally Pruess, supra note 60, at 1684 (noting the difficulty in fostering public acceptance of CCS capabilities and drawing analogies to other advanced technologies that pose exceedingly low risks of catastrophic failure but are nonetheless not accepted by the public). $\underline{(2005)}$.

Klass \& Wilson, supra note 17 , at $158-72$.

See James J. Dooley et al., Design Considerations for Financing a National Trust To Advance the Deployment of Geologic CO2 Storage and Motivate Best Practices, 4 Int'l J. Greenhouse Gas Control 381, 381-82 (2010) (discussing the inability of existing frameworks to adequately manage the type of long-term risks posed by CCS); Trabucchi \& Patton, supra note 26, at 2-3 (noting the inability of current financial risk-management regimes to manage CCS risk). 
See, e.g., Klass \& Wilson, supra note 17, at 103-04; Trabucchi \& Patton, supra note 26, at 16-17.

CCS Alliance, supra note 15, at 58; Interstate Oil \& Gas Compact Comm'n, Storage of Carbon Dioxide in Geologic Structures: A Legal and Regulatory Guide for States and Provinces 11 (2007) [hereinafter IOGCC], available at http://groundwork.iogcc.org/sites/default/files/2008-CO2-Storage-Legal-and-Regulatory-Guide-for-States-Full-Report.pdf; Holtkamp, supra note 15 , at 12 .

CCS Alliance, supra note 15 , at 58.

See, e.g., Greenpeace, supra note 1, at 30-31; Trabucchi \& Patton, supra note 26, at 22 (questioning whether "[i]f not held completely financially and legally responsible for future, long-term damages, the CCS operator will be less careful in their siting and operating decisions"); Livengood, supra note 1.

See Andrew Jordan \& Timothy O'Riordan, The Precautionary Principle in Contemporary Environmental Policy and Politics, in Protecting Public Health \& the Environment 15-19 (Carolyn Raffensperger \& Joel Tickner eds., 1999). One point of potential disagreement, which we will address later, could be environmentalists' objections to federal preemption of state laws and programs. See infra Part IV.A. prescriptions of the two schools are aligned for the types of "unilateral" harms at issue here and discussed further below. See, e.g., Gary Schwartz, Mixed Theories of Tort Law: Affirming Both Deterrence and Corrective Justice, 75 Tex. L. Rev. 1801,1821 (1997).

Charles D. Kolstad et al., Ex Post Liability vs. Ex Ante Safety Regulation: Substitutes or Complements, 80 Am. Econ. Rev. 888 , 888 (1990).

See, e.g., Marcel Boyer \& Donatella Porrini, The Choice of Instruments for Environmental Policy: Liability or Regulation?, in An Introduction to the Law and Economics of Environmental Policy: Issues in Institutional Design 245, 245-46 (Timothy Swanson ed., 2002); Paul Calcott \& Stephen Hutton, The Choice of a Liability Regime When There is a Regulatory Gatekeeper, 51 J. Envtl. Econ. Mgmt. 153, 161-62 (2006); Kolstad et al., supra note 124, at 889; Steven Shavell, Liability for Harm Versus Regulation of Safety, 13 J. Legal Stud. 357, 358 (1984). 
$\underline{127}$

$\underline{128}$

Kolstad et al., supra note 124 , at 888-89.

Thomas O. McGarity, The Complementary Roles of Common Law Courts and Federal Agencies in Producing and Using PolicyRelevant Scientific Information, 37 Envtl. L. 1027, 1029 (2007); Patrick W. Schmitz, On the Joint Use of Liability and Safety Regulation, 20 Int'l Rev. L. \& Econ. 371, 371-72 (2000); W. Kip Viscusi, Toward a Diminished Role for Tort Liability: Social Insurance, Government Regulation, and Contemporary Risks to Health and Safety, 6 Yale J. on Reg. 65, 65-66 (1989); Wendy E. Wagner, When All Else Fails: Regulating Risky Products Through Tort Litigation, 95 Geo. L.J. 693, 695-96 (2007).

See, e.g., David Rosenberg, Individual Justice and Collectivizing Risk-Based Claims in Mass-Exposure Cases, 71 N.Y.U. L. Rev. 210, 212-14 (1996); Shavell, supra note 126, at 357-58.

Rabin, supra note 28 , at 33 .

Shavell, supra note 126, at 359-64.

Id.

See Richard A. Posner, Economic Analysis of law 227-29 (8th ed. 2011); Gifford, supra note 107, at 615-18; Rabin, supra note 28, at 28-33; Viscusi, supra note 128, at 65-66.

Posner, supra note 133, at 86-89; Shavell, supra note 126, at 359; Wagner, supra note 128, at 697-98.

Shavell, supra note 126 , at $369-70$.

Id.

Id. at 359; see Viscusi, supra note 128, at 75-77 (observing that the tort system does not "undertake any fundamental risk-related research").

Gifford, supra note 107, at 617; Shavell, supra note 126, at 360-61.

Shavell, supra note 126 , at $360-61$.

Id. at 363 .

Clayton P. Gillette \& James E. Krier, Risks, Courts, and Agencies, 138 U. Pa. L. Rev. 1027, 1048-49 (1990).

Gifford, supra note 107, at 615-17; Rabin, supra note 28, at 32.

Gifford, supra note 107, at 640-43. 
Shavell, supra note 126 , at 364 ; Viscusi, supra note 128 , at $72-74$

Shavell, supra note 126, at 368-69; Viscusi, supra note 128, at 74 .

Kolstad et al., supra note 124, at 889; Viscusi, supra note 128, at 82-83.

See Kenneth S. Abraham, The Relation Between Civil Liability and Environmental Regulation: An Analytical Overview, 41 Washburn L.J. 379, 380-81 (2002); Rabin, supra note 28, at 29.

Abraham, supra note 147 , at 382; Rabin, supra note 28 , at 29-30.

Calcott \& Hutton, supra note 126, at 153, 161-62.

Sébastien Rouillon, Safety Regulation vs. Liability with Heterogeneous Probabilities of Suit, 28 Int'1 Rev. L. Econ. 133, 133-34 (2008).

Gifford, supra note 107, at 619-20; Rabin, supra note 28, at 43.

Rabin, supra note 28 , at 43 .

Abraham, supra note 147, at 380-81; Gifford, supra note 107, at 633; Rabin, supra note 28, at 40; Rosenberg, supra note 129, at 217-18.

Rabin, supra note 28 , at 45 .

Gifford, supra note 107, at 636.

See Shavell, supra note 126 , at 363.

See Gifford, supra note 107, at 640-42 (quoting Steven S. Cherensky, Shareholders, Managers, and Corporate R\&D Spending: An Agency Cost Model, 10 Santa Clara Computer \& High Tech L.J. 299, 328 (1994)); Gillette \& Krier, supra note 141, at 1040-41 (explaining managers' tendency to discount probabilities of long-term risk in favor of more tangible short-term gains).

Gifford, supra note 107, at 640-42.

See, e.g., Al H. Ringleb \& Steven N. Wiggins, Liability and Large Scale, Long-Term Hazards, 98 J. Pol. Econ. 574, 591-93 (1990). 
$\underline{160}$

See Gifford, supra note 107, at 644-47. One could also argue that it is unfair to shareholders to make polluters pay for delayed liability, as it has the potential to "impose[] the cost of remediation on those with the misfortune of having acquired stock from those who benefitted from the pollution." Id. at 642-43 (quoting Richard B. Belzer, Discounting Across Generations: Necessary, Not Suspect, 20 Risk Analysis 779, 788 (2000)).

See id. at 638 (using a discount rate of two percent).

Rabin, supra note 28, at 43 ; see Gifford, supra note 107 , at 685-87.

Price-Anderson Act, 42 U.S.C. $§ 2210$ (2006).

Black Lung Benefits Act, 30 U.S.C. $\$ \S 901-945(2006)$.

Gifford, supra note 107, at 687-89 (noting the difficulties under no-fault liability schemes in proving that a victim's injuries were caused by the designated compensable event); Rabin, supra note 28 , at 49 (describing criticisms of no-fault environmental liability schemes as being potentially overinclusive, underinclusive, inefficient, and inequitable).

See Gifford, supra note 107, at 697.

See Nicholas Stern, The Economics of Climate Change: The Stern Review 31-32 (4th prtg. 2008) (explaining why conventional discount rates should be rejected when intergeneration equity is at stake); Kenneth J. Arrow et al., Intertemporal Equity, Discounting, and Economic Efficiency, in Climate Change 1995: Economic and Social Dimensions of Climate Change 125, 13034 (1996) (discussing the methodological issues and controversies that surround debates over discount rates for analyzing the economics of climate change policies and risks); Partha Dasgupta, Commentary: The Stern Review's Economics of Climate Change, 199 Nat'l Inst. Econ. Rev. 4, 5-6 (2007) (describing different methods and rationales for setting discount rates); William D. Nordhaus, A Review of the Stern Review on the Economics of Climate Change, 45 J. Econ. Literature 686, 689-701 (2007) (examining and critiquing arguments for different discount rates when long-term harms associated with climate change are at stake); Solow, supra note 106, at 8-10 (describing the different methods used in setting discount rates and the normative issues raised).

Nordhaus, supra note 167 , at $689-90,692$.

See Gifford, supra note 107, at 697; Rabin, supra note 28, at 4.

Solow, supra note 106 , at 12 .

See, e.g., Maureen L. Cropper, et al., The Determinants of Pesticide Regulation: A Statistical Analysis of EPA Decision Making, 100 J. Pol. Econ. 175, 194-95 (1992) (finding that interventions by environmental groups had a greater impact than those by industry groups); Marisa Martino Golden, Interest Groups in the Rulemaking Process: Who Participates? Whose Voices Get Heard?, 8 J. Pub. Admin. Res. \& Theory 245, 262-63 (1998) (describing the influence of environmental public interest groups on agency rulemaking).

See, e.g., Gillette \& Krier, supra note 141, at 1039-42, 1067-70. 
173 We will not address potential conflicts and claims between landowners over impacts on their utilization of pore space caused by injection of $\mathrm{CO}_{2}$ from adjoining properties.

Id. at 106.

CCS Alliance, supra note 15, at 20; see also James T. Hamilton \& W. Kip Viscusi, How Costly is "Clean"? An Analysis of the Benefits and Costs of Superfund Site Remediations, 18 J. Pol'y Analysis \& Mgmt. 1, 22-24 (1999) (detailing the purported inefficiencies of site cleanups under Superfund); Judy \& Probst, supra note 21, at 236-38.

Menell, supra note 174, at 108; cf. Judy \& Probst, supra note 21, at 236-38 (discussing a broader range of statistics that suggest transaction costs vary by site over the course of its cleanup, and that they declined substantially over the course of Superfund history).

Menell, supra note 174 , at 107.

Margaret Kriz, The Superfund Saga, Nat'1 J., Oct. 21, 1995, at 2592.

IEA, supra note 2, at 15, 29-30, 38-39; see supra Part I.B.

See Federal Requirements Under the Underground Injection Control Program for Carbon Dioxide Geologic Sequestration Wells, 75 Fed. Reg. 77,230, 77,236 (Dec. 10, 2010).

See supra Part I.B.

Anna Alberini \& David H. Austin, Strict Liability as a Deterrent in Toxic Waste Management: Empirical Evidence from Accident and Spill Data, 38 J. Envtl. Econ. \& Mgmt. 20, 21 (1999).

Id. at 43-44.

Bruce A. Larson, Environmental Policy Based on Strict Liability: Implications of Uncertainty and Bankruptcy, 72 Land Econ. 33 , 35, 41 (1996).

See Thomas O. McGarity, Ctr. for Progressive reform, MTBE and the Need for Effective Tort Law 2-3 (2005), available at http:// www.progressivereform.org/articles/MTBE_506.pdf.

See, e.g., Jeffrey W. Moore, The Potential Law of On-Shore Geologic Sequestration of CO2 Captured from Coal-Fired Power Plants, 28 Energy L.J. 443, 482-83 (2007). 
Resources \& Envtl. L. 187, 188 (2003).

$\underline{189}$

$\underline{190}$

$\underline{191}$

$\underline{192}$

$\underline{193}$

$\underline{205}$

Michael J. Moran et al., MTBE and Gasoline Hydrocarbons in Groundwater of the United States, 43 Ground Water 615, 616, 61819 (2005).

See, e.g., Richard O. Faulk \& John S. Gray, Reunion in Salem: Updating the MTBE Saga, 36 Envtl. L. Rep. 10,667, 10,668 (2006).

See McGarity, supra note 186, at 11-13.

See id. at 2.

Moore, supra note 187, at 482-83; Greg B. Kail, Persistence Pays Off in MTBE Tussle, J. AWWA, Feb. 2006, at 77-78 (describing how defective product claims paved the way to large settlements against oil companies).

See Joseph F. Speelman, The MTBE Controversy: Defending Mass Tort Claims, 69 Def. Couns. J. 35, 35-37 (2002).

McGarity, supra note 186, at 11-13; see also Klass \& Wilson, supra note 17, at 143-44.

McGarity, supra note 186, at 11-13.

See IEA, supra note 2, at 15, 29-30, 38-39; IPCC, supra note 34, at 63 (describing the importance of economies of scale to reducing the costs of CCS); supra Part I.B.

See supra Part I.A.

See Dobbs, Torts, supra note 91, at 269-70 (describing the elements of a claim for negligence).

Restatement (Second) of Torts $§ 291$ (1965); James A. Henderson, Jr. et al., The Torts Process 175-78 (5th ed. 1999).

Klass \& Wilson, supra note 17, at 137.

See supra note 64 and accompanying text.

See Nicot \& Duncan, supra note 60 , at $17-18$.

See Abraham, supra note 147, at 387.

Id. at $381,386-87$. 
James A. Henderson et al., The Torts Process 380-81 (6th ed. 2003).

Id. at 379 .

See supra Part I.B.

Restatement (Second) of Torts $\S \S 821 \mathrm{D}-828$ (describing the elements of private nuisance).

See, e.g., Vill. of DePue v. Viacom Int'1, Inc., Nos. 08-cv-1272, 08-cv-1273, 2009 WL 1841582, at *9 (C.D. Ill. June 25, 2009) (finding that merely establishing a subsurface intrusion is sufficient to establish trespass).

See Owen L. Anderson, Subsurface “Trespass”: A Man's Subsurface Is Not His Castle, 49 Washburn L.J. 247,271 (2010) (describing cases of subsurface intrusion in which direct harm leads to a cause of nuisance).

Restatement (Second) of Torts $\S \S 821 \mathrm{D}-828$.

Dan B. Dobbs, Law of Remedies 765-71 (2d ed. 1993) [hereinafter Dobbs, Remedies] (discussing the balancing of benefits and harms in nuisance cases).

See id. at 767 (explaining how the degree of hardship is taken into account during the balancing test).

It is uncertain, however, whether owners of properties overlying a sequestration reservoir could succeed on a claim of "stigma" and seek compensation for diminished property value. Moore, supra note 187 , at $478-79$. But see Klass \& Wilson, supra note 17 , at 144-45 (suggesting that claims for stigma may be viable).

Restatement (Second) of Torts $\S \S 158-59$.

Anderson, supra note 211, at 270-72.

Moore, supra note 187 , at 478 .

See, e.g., Dobbs, Remedies, supra note 213, at 769-70 (noting that "[w]hen the defendant's conduct has violated a statute, it is possible that the legislature has already weighed the competing interests and has reflected its judgment in the statue," and that "[i]n such a case the court may be willing to discount its own assessment of public interest"). This contrasts with liability under negligence, which is treated as "per se" when a plaintiff demonstrates that a defendant was in violation of a regulatory standard, that the harm caused is the type of harm the governing statute was designed to mitigate, and that the plaintiff is within the class of people the statute was established to protect. Restatement (Third) of Torts: Liability for Physical Harm $§ 14$ (Proposed Final Draft 2005).

See Restatement (Third) of Torts: Liability for Physical Harm $§ 14$. 
221 Recall that release of brine will be driven by elevated pressures and very little bulk movement of brine is projected to occur. See supra Part I.B.

222 See Boudreaux v. Jefferson Island Storage, 255 F.3d 271, 275 (5th Cir. 2001) (holding that the migration of salt water injected into a mile-deep reservoir under plaintiff's property was not an actionable trespass, although plaintiff could obtain compensation for measurable damages if he had had any); Raymond v. Union Tex. Petroleum Corp., 697 F. Supp. 270, 273-75 (E.D. La. 1988) (same); see also Anderson, supra note 211, at 270-72 (discussing these and other cases addressing subsurface trespass).

223 See Alexandra B. Klass, From Reservoirs to Remediation: The Impact of CERCLA on Common Law Strict Liability Environmental Claims, 39 Wake Forest L. Rev. 903, 907-08 (2004) (discussing an early example of strict liability applied in an environmental context).

Id.

Restatement (Second) of Torts $\S 520$.

Posner, supra note 133 , at 227-28.

Id. at 228

Id.

Id.

Klass, supra note 223, at 904.

See, e.g., N.J. Dept. of Envtl. Prot. v. Ventron Corp., 468 A.2d 150 (N.J. 1983) (applying hindsight analysis); Prospect Corp. v. Singer Co., 569 A.2d 908, 911 (N.J. Super. Ct. Law Div. 1989).

See Elizabeth J. Wilson \& Mark A. de Figueiredo, Geologic Carbon Dioxide Sequestration: An Analysis of Subsurface Property Law, 36 Envtl L. Rep. 10,114, 10,123 (2006).

See Mark A. Geistfeld, The Doctrinal Unity of Alternative Liability and Market-Share Liability, 155 U. Pa. L. Rev. 447, 448-51 (2006).

Id.

Id. 
$\underline{236}$

$\underline{237}$

$\underline{238}$

Id.

Allen Rostron, Beyond Market Share Liability: A Theory of Proportional Share Liability for Nonfungible Products, 52 UCLA L. Rev. 151, $153(2004)$.

Restatement (Third) of Torts: Apportionment Liability $\S$ E18.

See Restatement (Third) of Torts: Apportionment Liability § 22.

Dan B. Dobbs, The Law of Torts 1085-87 (2000).

Id.

Posner, supra note 133 , at 227-29.

Sam Holloway, Underground Sequestration of Carbon Dioxide--A Viable Greenhouse Gas Mitigation Option, 30 Energy 2318, $2318(2003)$.

See IEA, supra note 2, at 15, 29-30, 38-39; IPCC, supra note 34, at 63 (describing the importance of economies of scale to reducing the costs of CCS); supra Part I.B.

Steven Shavell, Economic Analysis of Accident Law 6-8 (1987).

Id.

Id.

Oldenburg et al., Risk Assessment, supra note 63, at 10.

See supra Part I.B.

Posner, supra note 133 , at 227-29.

Id. at 229. The extent to which the costs would diverge would depend on the degree to which accidents are caused by negligence as opposed to being unavoidable; the more that they are unavoidable, the greater the divergence. Id.

See supra Part I.C.

See Posner, supra note 133, at 229 (explaining that a basic premise of strict liability is that, particularly for new industries, it 
provides efficient incentives for risk producers to locate their operations in regions that avoid the most significant risks).

Orr, supra note 35 , at 1656. Even low-end estimates find capacities that far exceed potential needs over the next few decades. Benson \& Surles, supra note 32, at 1796; Jordan K. Eccles et al., Physical and Economic Potential of Geological CO2 Storage in Saline Aquifers, 43 Envtl. Sci. \& Tech. 1962, 1967-69 (2009).

See supra Part I.B.

See supra Part I.A.

See Klass \& Wilson, supra note 17, at 141-43 (arguing that if sequestration of $\mathrm{CO}_{2}$ is considered a "matter of common usage" or "appropriate" use of the land, strict liability is unlikely to apply).

Id. at $142-43$.

Moore, supra note 187 , at 483 .

Id.

Id.

See CCS Alliance, supra note 15, at 20-21, 58 (discussing the potential applicability of CERCLA to $\mathrm{CO}_{2}$ leaks); Trabucchi et al., supra note 13 , at 388-89.

Klass \& Wilson, supra note 17 , at 132.

Id.

R.A. Chadwick et al., Review of Monitoring Issues and Technologies Associated with the Long-Term Underground Storage of Carbon Dioxide, 313 Geologic Soc'y London 257, 271-74 (2009). Further, significant uncertainties will exist about whether actual harm will materialize--making it difficult to seek preemptive injunctive relief--unless harm were defined as any movement of $\mathrm{CO}_{2}$ above a storage reservoir, which would subject site operators to many unnecessary challenges and potential holdups.

Id. at 271 .

See supra Part I.A.

See supra Part I.B.

Sally M. Benson \& Robert Hepple, Prospects for Early Detection and Options for Remediation of Leakage from CO2 Storage 
Projects, in 2 Carbon Dioxide Capture for Storage in Deep Geologic Formations--Results from the CO2 Capture Project 1189 , 1195-96 (Sally M. Benson ed., 2005). These characteristics also highlight the importance of site monitoring, operational decisions (for example, reducing or halting $\mathrm{CO}_{2}$ injection), and corrective actions (such as closing a subsurface fault). Id.

$\underline{270}$

$\underline{271}$

$\underline{272}$

Id. at $1195-1200$.

See supra Part I.B.

Zhou et al., supra note 22, at 509 (finding that lateral movement of brine would be very modest over the first 50 years of site operation).

Birkholzer \& Zhou, supra note 22, at 750 (simulation predicting that interaction between wells spaced $30 \mathrm{~km}$ apart would arise within a year and that reservoir-wide pressure effects were indivisible within 50 years).

Id.

See Nicot, Fresh-Water, supra note 22, at 589-90; Kalunka et al., supra note 20, at 4-5; Zhou et al., supra note 22, at 503-04.

See supra Part III.C.1.

See supra Part III.C.2.

See supra Part III.C.2.

See Oldenburg et al., Risk Assessment, supra note 63, at 10; Oldenburg et al., Certification Framework, supra note 33 , at 446. Further, because the geologic characteristics of better sites will make monitoring more effective, the quality of information will be higher at the best sites, which will in turn elevate the importance of operational decisions. Id.

See supra Part I.A.

Chadwick et al., supra note 265 , at 272-73. The injection process itself will provide much more reliable information about the characteristics of the reservoir (permeability, cap rock, pore space) than imaging methods can provide, and site operators will iteratively update and refine their models in response to this continuous flow of information. Id.

See, e.g., Richard Webster, Federal Environmental Enforcement: Is Less More?, 18 Fordham Envtl. L. Rev. 303, 314-18 (2006) (noting that resource constraints are a common phenomenon in all EPA programmatic areas).

Chadwick et al., supra note 265 , at 272-73.

The effectiveness of site monitoring, for example, will vary between sites. In general, the same properties that make reservoirs good for sequestration (for example, permeability and porosity) also enable more effective monitoring. See id. at 259, 272-73; 
Benson et al., supra note 97 , at 9 .

An enormous amount of literature exists on federalism as it relates to environmental regulation and common law liability, as well as on federalism issues generally. In this article, we cannot address all of the questions and likely objections to our preference for federal-level regulation, and we doubt that it is ultimately a question that can be decided definitively either way. See generally David E. Adelman \& Kirsten H. Engel, Adaptive Federalism: The Case Against Reallocating Environmental Regulatory Authority,

Federal Requirements Under the Underground Injection Control Program for Carbon Dioxide Geologic Sequestration Wells, 75 Fed. Reg. 77,230, 77,235 (Dec. 10, 2010).

Id.

Id.

Id. at 77,241 (describing the new regulations as establishing "minimum federal requirements" for geologic sequestration of $\mathrm{CO}_{2}$ ).

42 U.S.C. $\S \S 6901-6992$ (2006); Klass \& Wilson, supra note 17, at 126-28.

Klass \& Wilson, supra note 17 , at 125.

See id. (explaining duties under RCRA, which all relate to surface waste disposal).

Mandatory Reporting of Greenhouse Gases: Injection and Geologic Sequestration of Carbon Dioxide, 75 Fed. Reg. 75,060, 75,062-63 (Dec. 1, 2010) (setting reporting and monitoring requirements under the Clean Air Act).

Klass \& Wilson, supra note 17, at 130-32 (explaining why Superfund would not cover $\mathrm{CO}_{2}$ releases from sequestration sites); Marianne Horinko, The Global Env't \& Tech. Found. \& Am. Pub. Power Ass'n, Carbon Capture and Sequestration: Legal and Environmental Challenges Ahead 4 (2007), available at http://www.publicpower.org/files/PDFs/Attachment\%20\%236.pdf.

Robert V. Percival, et al., Environmental Regulation: Law, Science, and Policy 263-69 (3d ed. 2000) (describing the structure of CERCLA and procedures that govern cleanups).

Melisa F. Pollak \& Elizabeth J. Wilson, Regulating Geologic Sequestration in the United States: Early Rules Take Divergent Approaches, 43 Envtl. Sci. \& Tech. 3035, 3035 (2009); Thomas J. Russial, CCS: Legal and Regulatory Framework--10 Year Progress $\quad$ Report $\quad 71-72 \quad$ (Nov. 2010), http:// southwestcarbonpartnership.org/_Resources/PDF/Final\%20Verion_Nov_7_CCS\%20Legal\%C20and\%C20Regulatory\%C20Frame work\%C20Progress\% $\%$ Report.pdf.

CCS Alliance, supra note 15, at 58; Christopher Bidlack, Regulating the Inevitable: Understanding the Legal Consequences of and Providing for the Regulation of the Geologic Sequestration of Carbon Dioxide, 30 J. Land Resources \& Envtl. L. 199, 217-18 (2010); Wilson \& Figueiredo, supra note 232, at 10,123. 
92 Minn. L. Rev. 1796, 1801-13 (2008) (describing the competing theories in the federalism debate).

See Eccles et al., supra note 254, at 1968 (indicating that carbon sequestration is likely to be economically viable only for reservoirs in a relatively small number of states).

See generally David M. Konisky, Regulator Attitudes and the Environmental Race to the Bottom Argument, 18 J. Public Administration Research \& Theory 321, 327 (2008) (identifying Louisiana, Mississippi, Alabama, and Texas as states with the weakest enforcement of environmental regulations).

DOE Atlas, supra note 30, at 27.

See supra Part I.B.

Adelman \& Engel, supra note 298, at 1801-06.

See, e.g., John M. Broder, House Republicans Take E.P.A. Chief to Task, N.Y. Times, Feb. 10, 2011, at A16, available at http:// www.nytimes.com/2011/02/10/science/earth/10emissions.html; Paul Krugman, Op-Ed, Party of Pollution, N.Y. Times, Oct. 21, 2011, at A35, available at http:// www.nytimes.com/2011/10/21/opinion/party-of-pollution.html.

Similar kinds of limited preemption of state common law are not unprecedented. For example, under CERCLA, the 1986 Superfund Amendments and Reauthorization Act (SARA) added provisions that dictate the trigger date for statutes of limitations for certain common law actions. 42 U.S.C. $§ 9658$ (2006). Without changing state statutes of limitations themselves, SARA provides for a new commencement date for the "applicable limitation period;" specifically, the date the plaintiff knew (or reasonably should have known) that the personal injury or property damages were caused or contributed to by the hazardous substance or pollutant at issue. Id.; see Bolin v. Cessna Aircraft Co., 759 F. Supp. 692, 704 n.13 (D. Kan. 1991) (rejecting Tenth Amendment and Commerce Clause challenges to SARA).

\section{See supra Part II.A.}

See supra Part II.

DOE Atlas, supra note 30, at 26-29; see also Nicot \& Duncan, supra note 60, at 17-18.

See Oldenburg, Screening, supra note 64, at 1693 (describing a simplified framework for analyzing and ranking sequestration sites according to their safety based on just three basic site characteristics); Zhang et al., supra note 61, at 42 (describing a simple framework for estimating leakage risks from sequestration sites).

Andreas Kopp et al., A Contribution to Risk Analysis for Leakage Through Abandoned Wells in Geological CO2 Storage, 33 Advances in Water Resources 867, 878 (2010) (identifying the primary parameters for safety as depth and geothermal gradient, both of which can be measured readily at the regional level); S. Julio Friedmann, Site Characterization and Selection Guidelines for Geological Carbon Sequestration 5-9 (Lawrence Livermore Nat'1 Lab., Draft Document, 2007), available at https://e-reportsext.1lnl.gov/pdf/352172.pdf.

The rough site characterization contemplated here would be limited to determining factors such as injectivity (the rate at which 
$\mathrm{CO}_{2}$ could be sequestered) that are essential to the viability of a site but are also relatively simple and inexpensive to measure. See generally J.G. Kaldi \& C.M. Gibson-Poole, Coop. Research Ctr. for Greenhouse Gas Tech., Storage Capacity Estimation, Site Selection and Characterization for CO2 Storage Projects 19-21 (2008), available at http://www.co2crc.com.au/dls/pubs/081001_final.pdf; Kopp et al., supra note 310, at 878 .

Id. at 17-18.

Id. at 18-19.

Id.

See supra Part III.D.

See supra Part I.B.

Chadwick et al., supra note 265 , at 272-73.

See supra Part II.C.

Nicot \& Duncan, supra note 60, at 18 (noting that the fees generated could also be set aside to cover mitigation and remediation costs that arise after a site enters long-term stewardship).

See supra Parts I.A.-B.

See, e.g., U.S. Dep't of Energy, Carbon Sequestration Technology Roadmap and Program Plan 7-8 (2007), available at http:// www.netl.doe.gov/technologies/carbon_seq/refshelf/project\% 20portfolio/2007/2007roadmap.pdf; MIT, The Future of Coal: Options for a Carbon-Constrained World 52-54 (2007), available at http:// web.mit.edu/coal/The_Future_of_Coal.pdf.

American Clean Energy and Security Act of 2009, H.R. 2454, 111 th Cong. (2009).

See 33 U.S.C. $\S 2704(2010)$.

Figueiredo et al., supra note 61, at 9-10; Klass \& Wilson, supra note 17, at 171.

See H.R. 2454 (as passed by the House of Representatives on June 26, 2009). 
328 Gregory Singleton, Public Risk Perceptions on the Geologic Storage of Carbon Dioxide, 3 Int'l J. Greenhouse Gas Control 100 , 104-06 (2009); Richard Van Noorden, Buried Trouble, 463 Nature 871, 871 (2010); Paul Voosen, A Town's Lonely Struggle Shows CO2 Fears Here to Stay, N.Y. Times, May 11, 2010, available at http://www.nytimes.com/gwire/2010/05/11/11 greenwirea-towns-lonely-struggle-shows-co2-fears-here-to-218.html?pagewanted=all.

McGarity, supra note 128, at 1029; Wagner, supra note 128, at 695-97.

$\underline{330}$

See, e.g., Wagner, supra note 128, at 697-98 (describing the strategic concealment of information that businesses use to avoid regulation and potential liability); see also id. at 696 (discussing the role of tort litigation in lowering information barriers by both catalyzing research and forcing industry to disseminate information). 